\title{
Numerical analysis on the oscillation of stall cells over a NACA 0012 aerofoil
}

\author{
Dajun Liu and Takafumi Nishino \\ School of Water, Energy and Environment, Cranfield University \\ Cranfield, Bedfordshire, MK43 OAL, UK \\ dajun.liu@cranfield.ac.uk
}

\begin{abstract}
A series of three-dimensional unsteady Reynolds-averaged Navier-Stokes (RANS) simulations are conducted to investigate the formation and oscillation of stall cells over a NACA 0012 aerofoil. The simulations are conducted with various physical and numerical conditions, such as the Reynolds number, angle of attack, chord-to-span ratio and span-wise mesh resolution. Results show a clear relationship between the oscillation of stall cells and the fluctuation of lift (observed between 17 and 19.5 degrees angle of attack at a high chord Reynolds number of one million). This unsteadiness shows some dependency on the span-wise mesh resolution; it is significant with a medium span-wise mesh resolution (corresponding to $10 \%$ of the chord) and moderate with finer resolutions (corresponding to $5 \%$ and $2.5 \%$ of the chord, respectively). In addition, a proper orthogonal decomposition (POD) method is adopted to further analyse the oscillatory characteristics of stall cells. In particular, it is shown that the first few POD modes have clear spatial patterns corresponding to the profile of stall cells and their time coefficients are correlated with the fluctuation of lift, further confirming the correlation between the stall cell oscillations and the lift fluctuation.
\end{abstract}

KEYWORDS: Flow separation; 2D-3D transition; Lift fluctuation; Unsteady RANS; Proper orthogonal decomposition

\section{INTRODUCTION}

Stall cells are three-dimensional flow structures characterised by counter-rotating vortices generated on the suction side of an aerofoil in stall, also known as 'owl's eyes' or 'mushroomshaped' structures. It was Moss and Murdin [1] who first observed this type of flow structures in a series of wind tunnel tests on a NACA 0012 aerofoil in 1968. In almost 50 years of research, some features of this structure have been investigated, although the complete mechanism still remains unclear.

\subsection{Influential Factors of Stall Cell Formation}

The shape of the aerofoil plays a key role in the formation of stall cells. Broeren and Bragg [2] performed a series of experiments with five different aerofoil profiles. Only the aerofoils with a trailing-edge stall type (Ultra-Sport) or a leading-edge stall type (NACA 2414) generated stall cells. Stall cells were not observed on aerofoils with 'thin-aerofoil stall' type (NACA64A010, LRN-1007 and E374), in which a separation bubble near the leading edge was formed and a two-dimensional unsteady flow field was detected. 
The aspect ratio (AR) of the planform may affect the number of stall cells generated and their unsteadiness. Yon and Katz [3] found experimentally that the number of stall cells generated on an aerofoil increased linearly with AR. This was consistent with the result of an earlier study by Winkelman and Barlow [4]. Moreover, the stability of the stall cells was dependent on whether there were an integer number of stall cells formed on the aerofoil. For AR that allows 'half' stall cell to form, the structures became unsteady and moved along the chord-wise direction.

Gross et al. [5] developed a theoretical model for the prediction of stall-cell spacing, which supported the linear relationship between the number of stall cells and aerofoil AR found in [3]. This model also predicts that stall cells are formed with a negative gradient of lift coefficient $\left(C_{L}\right)$ versus angle of attack (AoA), which was further verified recently by Manni et al. [6] in a series of unsteady RANS simulations. However, according to the experiments by Broeren and Bragg [2], the stall cell formation may happen even with a rather flat $C_{L}$-AoA relationship. The range of AoA that allows stall cell formation is usually rather limited. Results of experiments conducted by Zarutskaya and Arieli [7] suggested that they only existed within 2-3 degrees. This was also supported by the recent CFD study [6].

On the unsteadiness of stall cells, Yon and Katz [3] stated that the stall cells underwent 'jostling' motion and trailed downstream. A similar motion was observed by Rodriguez and Theofilis [8] [9] in Direct Numerical Simulations (DNS) of laminar separated flow, where periodic stretching and compression of a span-wise vortex were found. In another experimental study by Disotell et al. [10], stall cells were formed on a DU97-W-300 aerofoil and the largeamplitude pressure fluctuations were detected by pressure-sensitive paint, which suggested unsteadiness of the stall cells. Manolesos et al. [11] performed both experimental and numerical work and reported that stall cells possibly started normal to the wing surface and gradually became parallel to the free stream and finally extended downstream in the wake. In addition, Zarutskaya and Arieli [7] detected span-wise motion of stall cells in their experiments. Nevertheless, Broeren and Bragg [2] stated that stall cell motion was not detected in their experiments. Their statement was supported by the experimental work of Elimelech et al. [12] and Dell' Orso et al. [13]. Recent experiments conducted by Ragni and Ferreira [14] observed the formation process of stall cells and that once they were generated, they remained stationary.

There is no clear explanation for the disagreement on the occurrence of stall cell motion. However, Disotell et al. [10] stated that the oil-visualisation technique employed in most experiments was a 'time averaged' method. The lack of sensitivity to high frequency oscillations may have caused the inability to observe such oscillatory flow patterns.

In this paper, a parametric unsteady RANS study of stall cell formation on a NACA 0012 aerofoil is conducted. The impact of the Reynolds number, aspect ratio, span-wise mesh resolution and the angle of attack on the formation and unsteadiness of stall cells is explored.

\subsection{Proper Orthogonal Decomposition}

In the study of fluid dynamics in recent years, more attention has been drawn to the so-called modal analysis, which involves modal decomposition of a flow field obtained from experimental or numerical results. Among many techniques, proper orthogonal decomposition (POD) is widely used in fluid flow analysis. POD was invented by Karl Pearson [15] and first introduced to analyse coherent structures in turbulent flow by Lumley [16]. Depending on its applied field, POD is also called principal component analysis, discrete Kosambi-Karhunen- 
Loeve transform (KLT), the Hotelling transform, empirical orthogonal functions, empirical eigenfunction decomposition, empirical component analysis, etc.

POD provides spatial modes of a flow field ranked by their kinetic energy level. The incoherent noise from the data can simply be removed by ignoring high-order (low kinetic-energy level) modes. The computational cost is fairly low even for high-dimensional spatial data sets. It can be used in the post-processing of various types of flows: boundary layer transition [17], jets in crossflow [18], flow separation and reattachment [19], and vortex shedding [20] [21]. It can also be employed for flow field reconstruction from incomplete experimental data [22], determination of the proper inlet condition of a flow [23], and helping finding control methods as an assist of other modal analysis [24].

In this study, POD analysis is applied to the velocity field above the aerofoil surface to extract dominant spatial modes. The relationship between POD modes and stall cell oscillation is illustrated.

\section{Methodology}

\subsection{Flow Configurations}

This study investigates the airflow over a NACA 0012 aerofoil with one-metre chord length. Five different span-wise lengths $(2.5,3.2,4,6.4$ and 10 chords) are tested to investigate the influence of the aspect ratio, with periodic boundary conditions applied to the span-wise direction. The air density is $1.225 \mathrm{~kg} / \mathrm{m}^{3}$, and the viscosity is $1.7894 \times 10^{-5} \mathrm{~kg} /(\mathrm{m} \cdot \mathrm{s})$. The freestream velocity $U_{\infty}$ is set as $1.97 \mathrm{~m} / \mathrm{s}$ and $14.607 \mathrm{~m} / \mathrm{s}$, respectively, for two different chord Reynolds number cases, $R e=1.35 \times 10^{5}$ and $R e=1 \times 10^{6}$. A Cartesian coordinate system $(x, y$, $z$ ) is employed to describe the local coordinate, i.e. $x$ and $y$ denote the direction parallel and perpendicular to the chord line, respectively, and $z$ is the span-wise direction.

\subsection{Computational Domain and Mesh}

A fully structured 2D circular mesh with a 50-chord radius is generated first with 436 nodes around the aerofoil and 155 nodes along the radial direction, which gives a total of approximately 68,000 nodes. Figure 1 shows a closer view of the high Reynolds number mesh around the aerofoil. The first node distance from the aerofoil surface is set as $1 \times 10^{-4}$ chord for the low $R e$ cases and $8 \times 10^{-6}$ chord for the high $R e$ cases to make sure $y^{+}<1$ for all walladjacent cells.

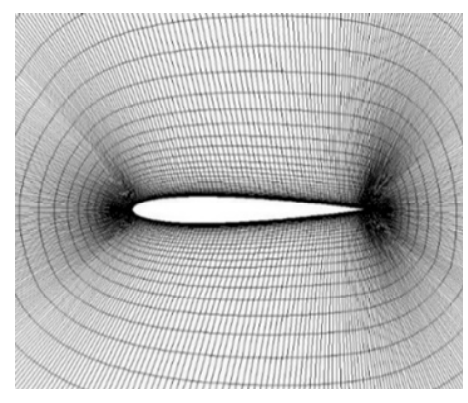

Figure 1. Mesh around the aerofoil.

The mesh sensitivity has been investigated for $2 \mathrm{D}$ simulations with $\operatorname{Re}=1 \times 10^{6}$ at $\mathrm{AoA}=1^{\circ}$ to $20^{\circ}$, with four different mesh resolutions. The original mesh (G2) is coarsened once with half the total nodes (G1) and refined twice, each time with double the total nodes (G3, G4) 
while keeping the same first node distance from the aerofoil surface. As summarised in Figure $2, \mathrm{G} 1$ is apparently not sufficient to predict $C_{L}$ accurately. Although the $C_{L}$ value around the stall angles slightly changes with each refinement from $\mathrm{G} 2$ to G4, the mesh with approximately 68,000 nodes (G2) is adopted in this study taking both accuracy and computational cost into consideration. The sensitivity to the time step size is also tested with three different time step sizes: $0.0005 \mathrm{~s}, 0.001 \mathrm{~s}$, and $0.002 \mathrm{~s}$. In terms of lift and drag coefficients, the time step size does not appear to have any influence on the results; therefore $0.001 \mathrm{~s}$ is chosen for the rest of the study.

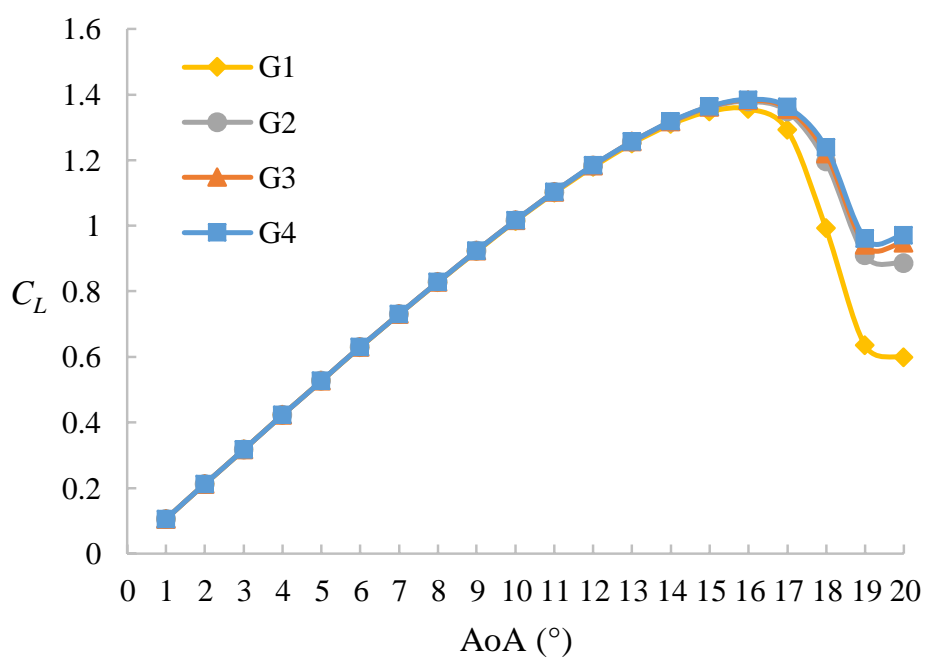

Figure 2. Grid dependency of 2D aerofoil lift coefficients. $R e=1 \times 10^{6}$.

Another set of 2D simulations has also been performed for the lower Reynolds number $(R e=$ $\left.1.35 \times 10^{5}\right)$ with the selected mesh (G2) and time step size (0.001s). The lift coefficients are compared with the experimental results of Lee and Gerontakos [25] and the numerical results of Shen et al. [26], as shown in Figure 3. Although there are some differences to the experimental results in the stall angle and the $C_{L}$ value at high angles of attack, the results are satisfactory overall, considering that the results agree well with the numerical results of Shen et al. [26]. The small discrepancy between the experimental and numerical results at low angles of attack could be due to the very low free-stream turbulence intensity $(0.08 \%)$ adopted in the experiments.

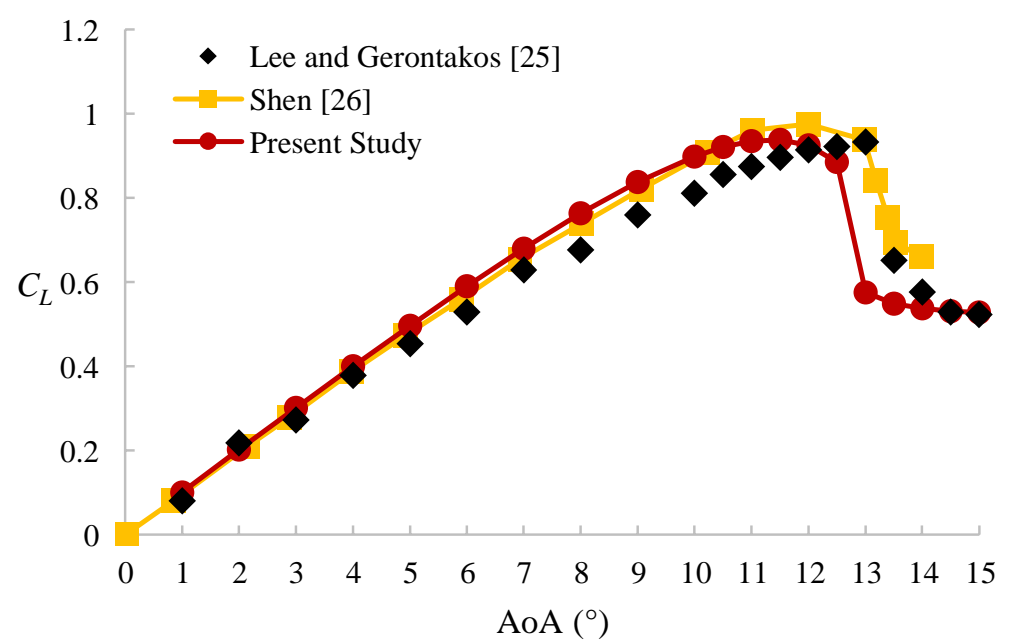

Figure 3. $C_{L}$ comparison between $2 \mathrm{D}$ simulations and experiments. $R e=1.35 \times 10^{5}$. 
The 3D mesh is generated by extruding the $2 \mathrm{D}$ mesh in the span-wise direction with a constant resolution of $10 \%$ of the chord. Three additional cases with halved (20\% chord), doubled (5\% chord) and quadrupled (2.5\% chord) resolution are also conducted in order to illustrate the influence of the span-wise resolution $(\Delta \mathrm{z})$. An overview of the computational domain is shown in Figure 4.

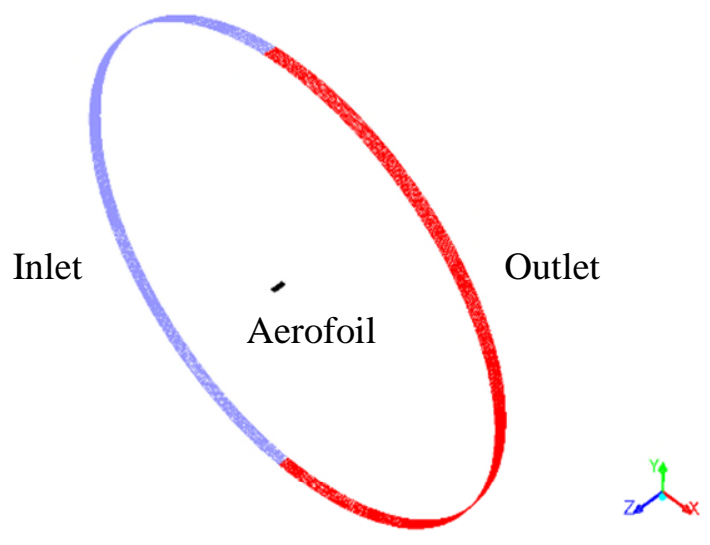

Figure 4. Computational domain for $\mathrm{AR}=2.5$.

\subsection{Flow Solver}

Simulations are performed on ANSYS FLUENT 17.1. The incompressible unsteady Reynoldsaveraged Navier-Stoke (RANS) equations are solved using the (fully turbulent, not transitional) SST $k-\omega$ turbulence model [27]. The choice of the turbulence model is based on the second author's previous research [6] for consistency. The second-order upwind scheme is used for spatial discretisation and a second-order implicit scheme for time discretisation. SIMPLE algorithm is adopted for the pressure-velocity coupling. Periodic conditions are employed in the span-wise direction to simulate an infinitely long wing. A uniform velocity is specified at the inlet boundary to meet the Reynolds number requirements noted in Section 2.1. At the outlet, the boundary condition is set as 'pressure outlet' with a gauge pressure of $0 \mathrm{~Pa}$ to simulate an atmospheric environment. As for the turbulence condition, the turbulence intensity and viscosity ratio at the inlet is set as $1 \%$ and 1 respectively to simulate a low turbulence level flow. Each simulation is performed until the flow evolves into a statistically converged state, before calculating the time-averaged flow and taking snapshots for the POD analysis.

\subsection{POD Procedure}

The snapshot POD method was introduced by Sirovich [28] and is particularly suitable for a large set of flow field data. In this study, stream-wise (or chord-wise) velocity field over the suction side of the aerofoil is analysed at three planes perpendicular to the chord line, $x / c=0.2$ (Plane 1), 0.5 (Plane 2) and 0.8 (Plane 3), to explore the time-dependent characteristics of stall cells. Note that it would be interesting to conduct a POD analysis of the entire flow field around the aerofoil; however, this would require very large computational resources and was not feasible in this study. All flow field data are first imported into ANSYS CFD-POST 16.0, on which the three planes are created to sample velocity data. Snapshots of time-dependent stream-wise velocity field $u(t)$ are taken on each plane for a period corresponding to ten full cycles of stall cell oscillation process and ten cycles of $C_{L}$ fluctuation (to be presented in Section 3). The number of snapshots $m$ is 100 for each case. After collecting these samples, snapshot POD is performed using the following procedure in MATLAB R2016b: 
1) Take samples of instantaneous stream-wise velocity field $u(t)$.

2) Stack the velocity field $u(t)$ into a matrix form of

3) Solve the eigenvalue problem;

$$
\boldsymbol{U}=\left[u\left(t_{1}\right) u\left(t_{2}\right) \ldots u\left(t_{m}\right)\right]
$$

4) Calculate the POD modes;

$$
\boldsymbol{U}^{\boldsymbol{T}} \boldsymbol{U} \psi_{m}=\lambda_{m} \psi_{m}
$$

$$
\phi_{j}=\boldsymbol{U} \psi_{j} \frac{1}{\sqrt{\lambda_{j}}}, j=1,2, \ldots, m
$$

5) Calculate the temporal coefficients;

$$
a_{j}(t)=<u(t), \phi_{j}>, j=1,2, \ldots, m
$$

6) Normalise the POD modes:

$$
P_{j}=\frac{\sum_{j}\left|a_{j}\right|}{m} \frac{\phi_{j}}{U_{\infty}}, j=1,2, \ldots, m
$$

The MATLAB code is modified from a publicly available code of Chen et al. [29]. The nondimensionalised and normalised POD modes at each plane are visualised as contours using Gnuplot 5.0. 


\section{RESUlts AND DiscuSsion}

In this section, 3D simulation results are presented to analyse the stall cell formation and oscillations. Different Reynolds numbers, aspect ratios and span-wise resolutions are adopted to investigate influential factors for stall cell formation and oscillations. Table 1 shows a summary of flow conditions for all cases.

Table 1 Summary of 3D Simulation Cases

\begin{tabular}{ccccc}
\hline Case No. & $\begin{array}{c}\text { Reynolds } \\
\text { Number }\end{array}$ & $\begin{array}{c}\text { Aspect } \\
\text { Ratio }\end{array}$ & $\begin{array}{c}\text { Span-wise } \\
\text { Resolution }(\Delta \mathbf{z})\end{array}$ & $\begin{array}{c}\text { Angle of } \\
\text { Attack }\left(^{\circ}\right)\end{array}$ \\
\hline 1 & $1.35 \times 10^{5}$ & 2.5 & $0.1 \mathrm{c}$ & 12.5 \\
2 & $1.35 \times 10^{5}$ & 2.5 & $0.1 \mathrm{c}$ & 12.75 \\
3 & $1.35 \times 10^{5}$ & 2.5 & $0.1 \mathrm{c}$ & 13 \\
4 & $1 \times 10^{6}$ & 2.5 & $0.1 \mathrm{c}$ & 17 \\
5 & $1 \times 10^{6}$ & 2.5 & $0.1 \mathrm{c}$ & 17.5 \\
6 & $1 \times 10^{6}$ & 2.5 & $0.1 \mathrm{c}$ & 18 \\
7 & $1 \times 10^{6}$ & 2.5 & $0.05 \mathrm{c}$ & 18 \\
8 & $1 \times 10^{6}$ & 2.5 & $0.025 \mathrm{c}$ & 18 \\
9 & $1 \times 10^{6}$ & 2.5 & $0.1 \mathrm{c}$ & 18.5 \\
10 & $1 \times 10^{6}$ & 2.5 & $0.1 \mathrm{c}$ & 19 \\
11 & $1 \times 10^{6}$ & 2.5 & $0.1 \mathrm{c}$ & 19.5 \\
12 & $1 \times 10^{6}$ & 3.2 & $0.1 \mathrm{c}$ & 18 \\
13 & $1 \times 10^{6}$ & 4 & $0.1 \mathrm{c}$ & 18 \\
14 & $1 \times 10^{6}$ & 6.4 & $0.1 \mathrm{c}$ & 18 \\
15 & $1 \times 10^{6}$ & 10 & $0.1 \mathrm{c}$ & 18 \\
16 & $1 \times 10^{6}$ & 10 & $0.2 \mathrm{c}$ & 18 \\
17 & $1 \times 10^{6}$ & 10 & $0.05 \mathrm{c}$ & 18 \\
\hline
\end{tabular}

\subsection{Low Reynolds Number Cases}

For the lower Reynolds number cases (Case 1-3), stall cell structures are observed only at 12.75 degree. Figure 5 shows the history of the (span-wise averaged) lift coefficient for Case 1-3. After a certain time of simulation, both $12.5^{\circ}$ and $13^{\circ}$ cases stabilise with very little fluctuation, while $12.75^{\circ}$ case shows obvious periodic oscillation, which corresponds to the development of stall cells. Figure 6 shows selected instantaneous skin-friction lines (coloured based on the wall shear stress in the stream-wise direction) from one cycle of $C_{L}$ fluctuation (51s to 56s). It can be seen that the counter-rotating vortex pair forms near the leading edge, travels downstream, and decays at the trailing edge. As will be presented below for the high Reynolds number cases, the fluctuation of $C_{L}$ and the oscillation of stall cell structures are directly related to each other. 


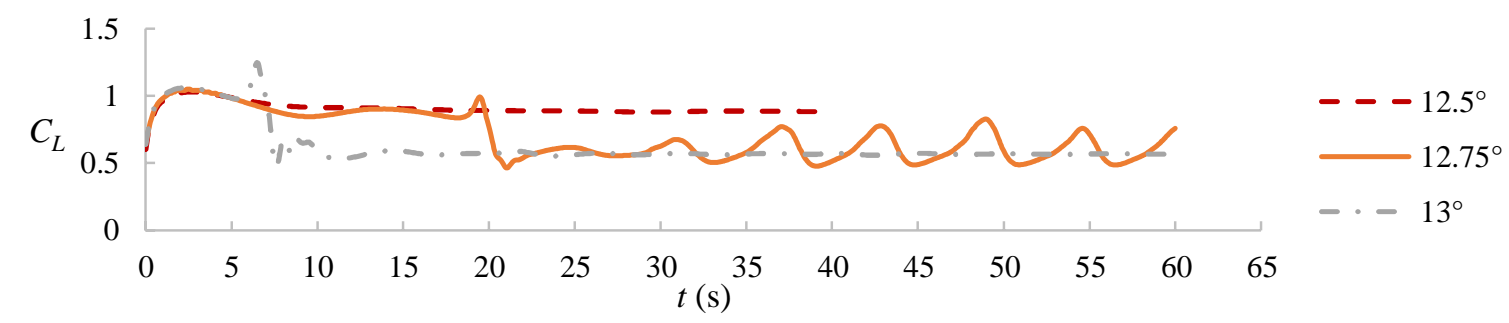

Figure 5. Time history of $C_{L}$ at $R e=1.35 \times 10^{5}$. AoA $=12.5^{\circ}, 12.75^{\circ}$, and $13^{\circ}$. Case 1-3.
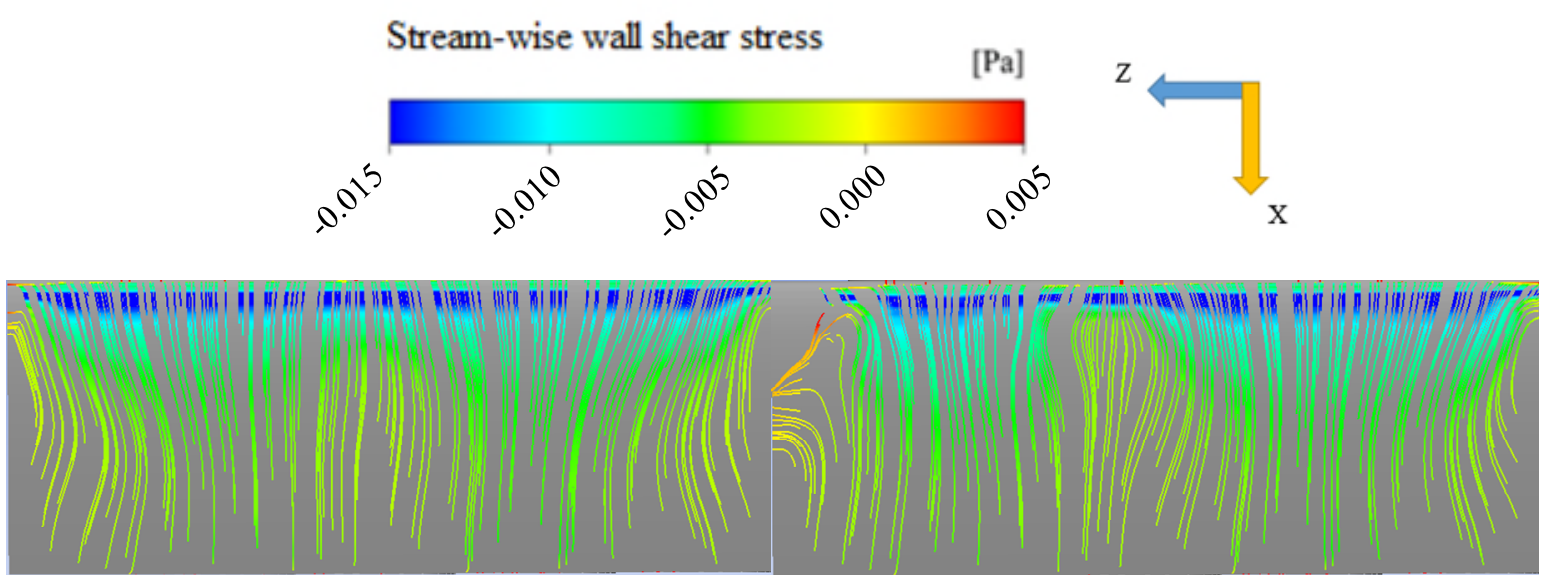

(a) $t=51 \mathrm{~s}$

(b) $t=52 \mathrm{~s}$

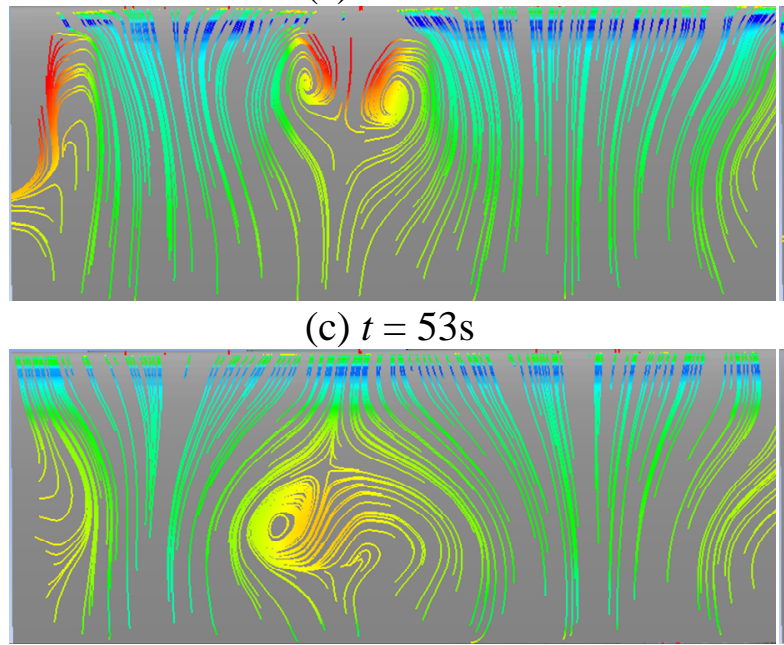

(e) $t=55 \mathrm{~s}$

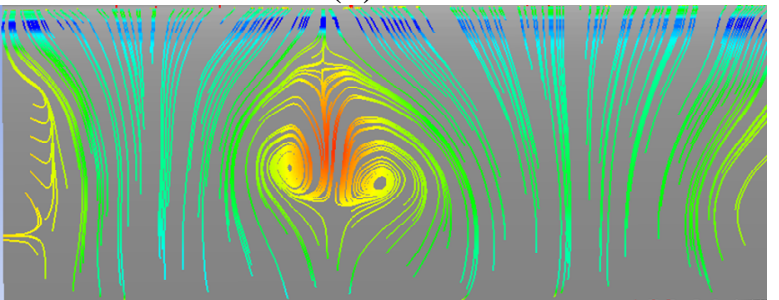

(d) $t=54 \mathrm{~s}$

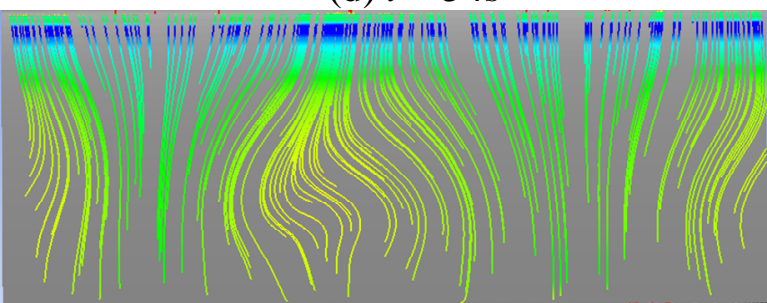

(f) $t=56 \mathrm{~s}$

Figure 6. Stall cell oscillation. $R e=1.35 \times 10^{5}$, AoA $=12.75^{\circ}, t=51-56 \mathrm{~s}$. Case 2 .

\subsection{High Reynolds Number Cases}

Figure 7 shows the mean $C_{L}$ comparison of the present study with $\mathrm{AR}=2.5$ and $\Delta \mathrm{z}=0.1 \mathrm{c}$ cases (Case 4-6, 9-11) and results of N50 and N200 from [6] for a range of AoA at which the formation of stall cells are observed. In [6], four different span-wise resolutions are tested: N10, $\mathrm{N} 20, \mathrm{~N} 50, \mathrm{~N} 200$, which respectively correspond to span-wise resolutions of 1, 0.5, 0.2 and 0.05 chords. It should also be noted that $A R=10$ was employed in [6]. The results of the present simulations (with $\Delta \mathrm{z}=0.1 \mathrm{c}$ ) lie between N50 and N200 results of [6], which suggests the consistency of the present study with [6]. Figure 7 also suggests that the effect of AR on the mean lift coefficient is insignificant and that the mean lift coefficient tends to decrease slightly and monotonically as we increase the span-wise mesh resolution. 


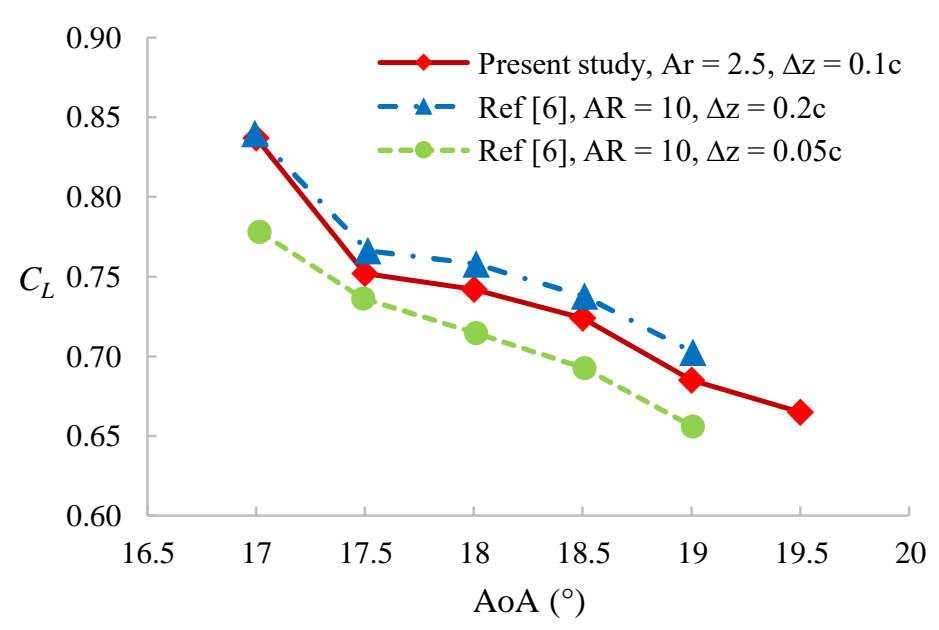

Figure 7. Mean lift coefficient comparison. $R e=1 \times 10^{6}, \mathrm{AR}=2.5, \Delta \mathrm{z}=0.1 \mathrm{c}($ Case 4-6, 911).

Similarly to the low Reynolds number cases, for this range of AoA $\left(17^{\circ}-19.5^{\circ}\right)$, the lift coefficient starts oscillating after a certain time of simulation. Figure 8 shows the (span-wisely averaged) $C_{L}$ time history of Case 7 and 15 as an example. Figure 9 shows the visualisation of stall cells for Case 5-10, taken at a peak- $C_{L}$ time step for each case.

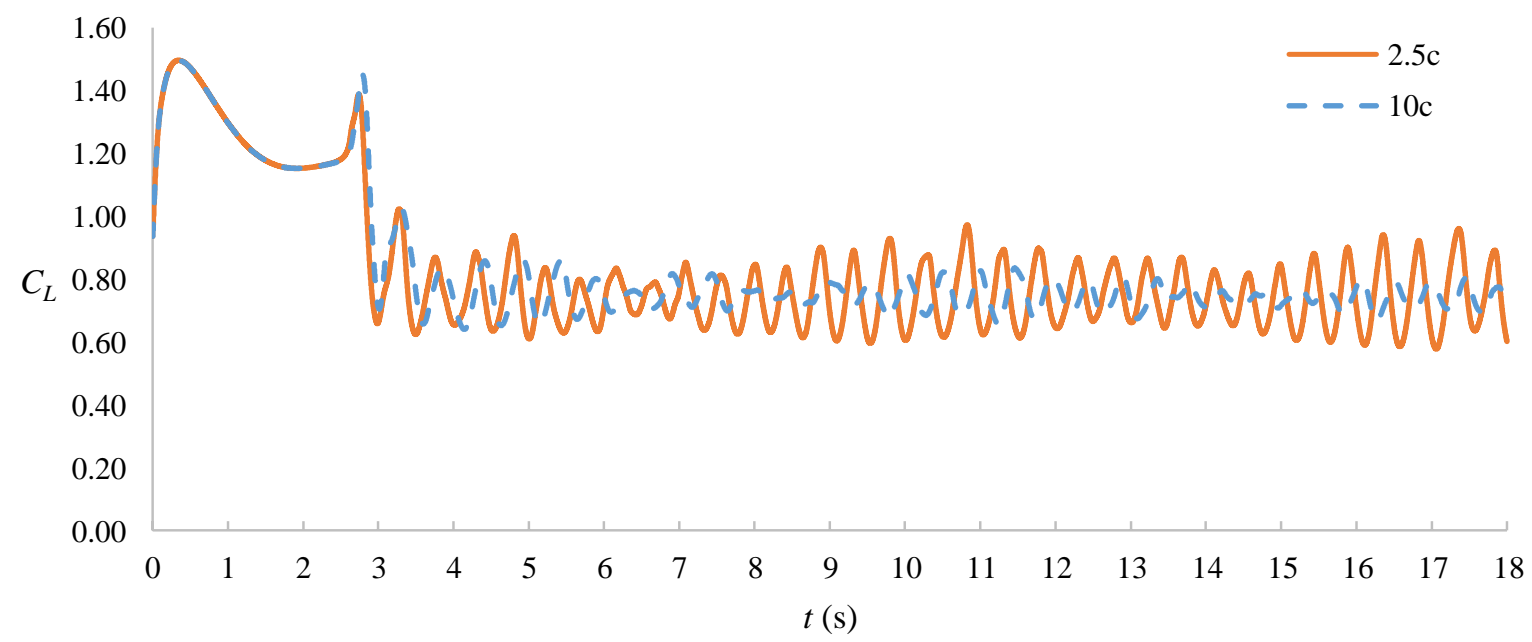

Figure $8 C_{L}$ time history. $R e=1 \times 10^{6}, \mathrm{AR}=2.5 \& 10, \mathrm{AoA}=18^{\circ}, \Delta \mathrm{z}=0.1 \mathrm{c}($ Case 6 and $15)$. 


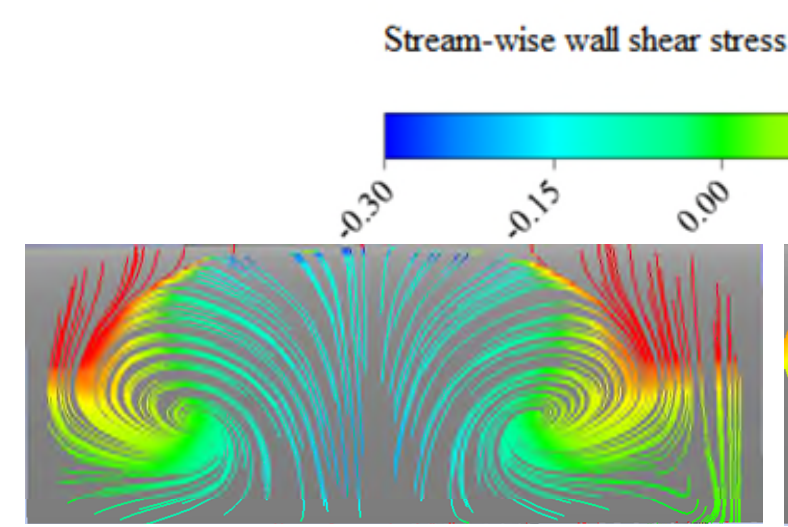

(a) $17^{\circ}$

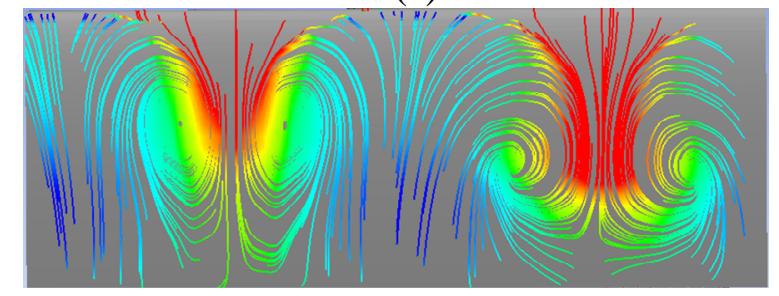

(c) $18^{\circ}$

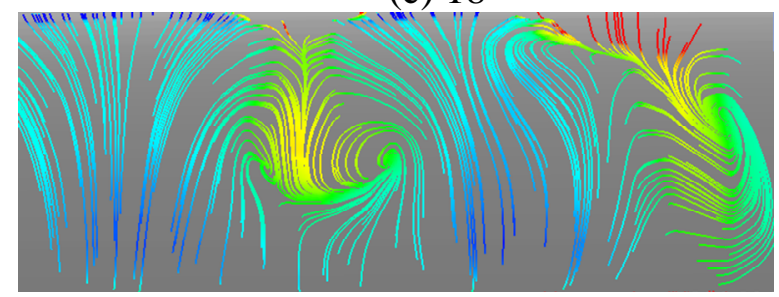

(d) $19^{\circ}$

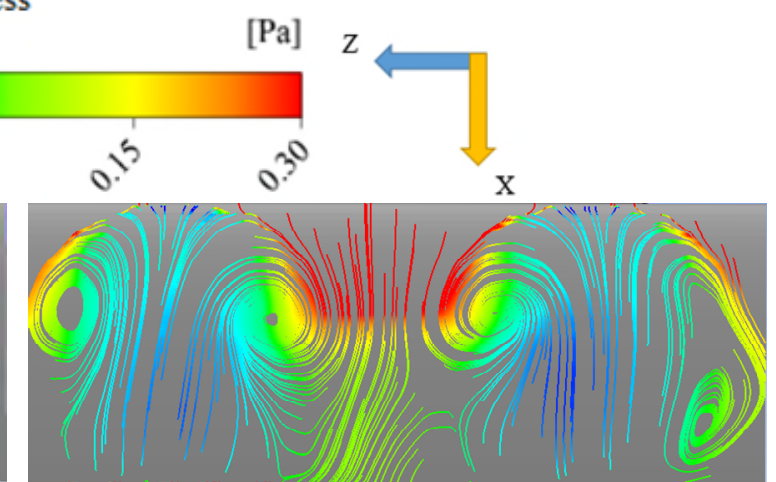

(b) $17.5^{\circ}$

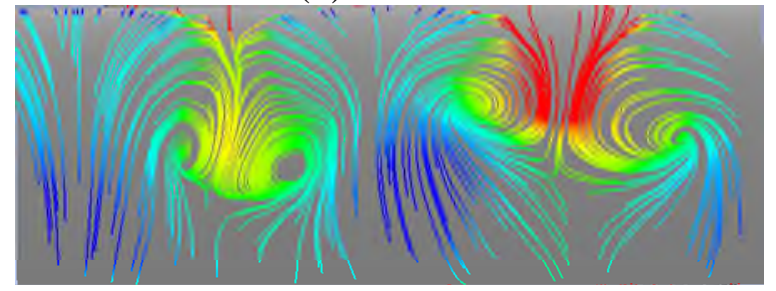

(d) $18.5^{\circ}$

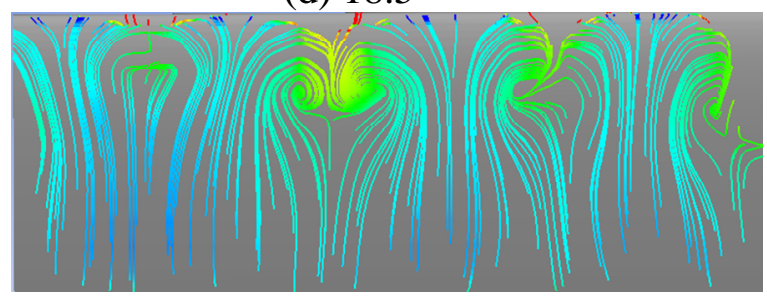

(f) $19.5^{\circ}$

Figure 9. Visualisation of stall cells at a peak- $C_{L}$ time, $\mathrm{AR}=2.5, \operatorname{Re}=1 \times 10^{6}, \Delta \mathrm{z}=0.1 \mathrm{c}$

(Case 4-6, 9-11).

Correspondingly to the lift oscillation, flow structures on the aerofoil surface also show a periodic oscillating pattern. Figure 10 (left) shows a series of snapshots taken from one cycle of lift oscillation of Case $6(t=8.33 \mathrm{~s}-8.64 \mathrm{~s})$, and the lift coefficient corresponding to each flow time. It clearly illustrates the movement of stall cells, which follows a routine similar to the lower Re case presented earlier: forming near the leading edge, traveling towards the trailing edge, and disappearing near the trailing edge. These flow patterns travel only along the chord-wise direction. No movement in the span-wise direction is observed.

In this range of AoA, the flow appears to be at an intermediate state between 'attached' and 'separated'. As shown in Figure 10 (left), when $C_{L}$ goes up, meaning that the flow is changing towards 'attached', stall cell structures become clearer near the leading edge. When $C_{L}$ peaks, the stall cells are most clearly observed. We can see a large region of attached flow (red) between two stall cells. When $C_{L}$ goes down, meaning that the flow is changing towards 'separated', clear stall cell patterns travel to the trailing edge region and then become unclear, while the attached flow between two cells also diminishes. In other words, the attached region between the two cells repeatedly increases and decreases, making the stall cell structures clearer and less clear. This is also confirmed from the stream-wise velocity field above the aerofoil on the mid-chord plane (Plane 2) shown in Figure 10 (right). It can be observed that the velocity field above the aerofoil (especially the attached flow region) keeps fluctuating, which corresponds to the stall cell oscillation. 

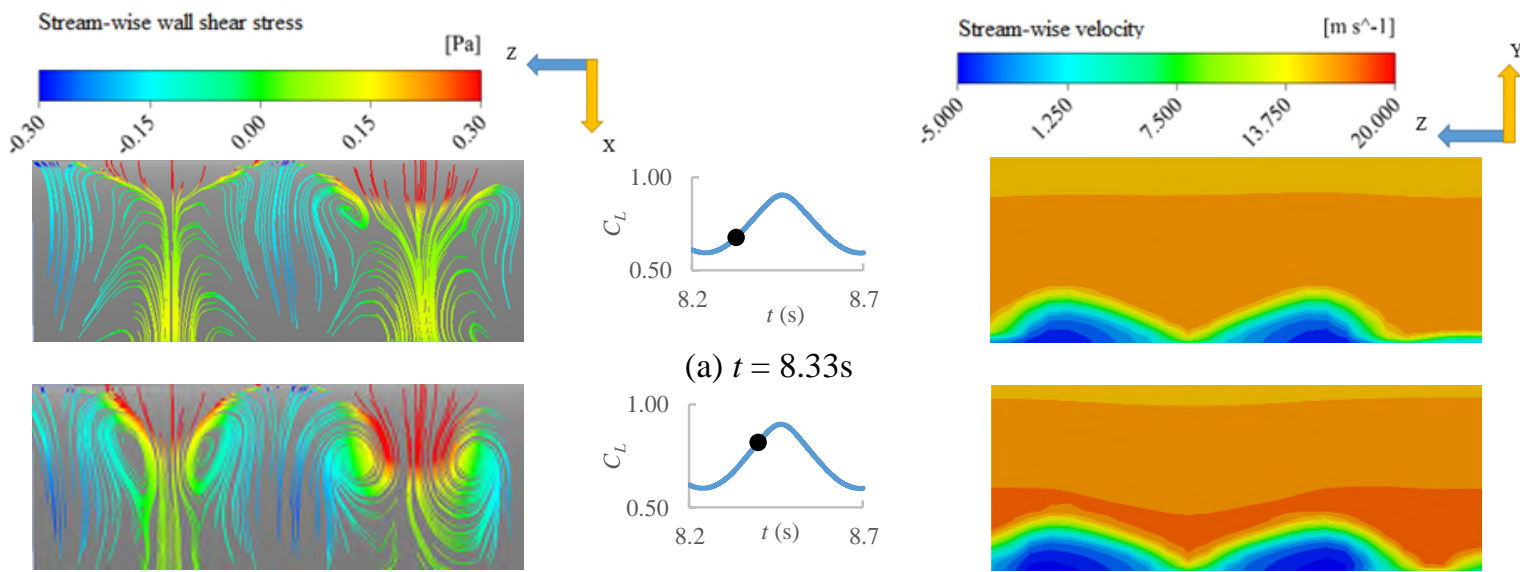

(a) $t=8.33 \mathrm{~s}$
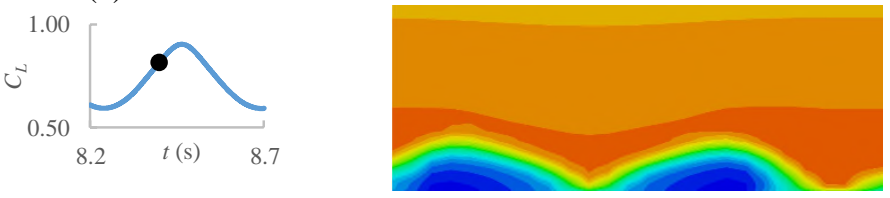

(b) $t=8.40 \mathrm{~s}$
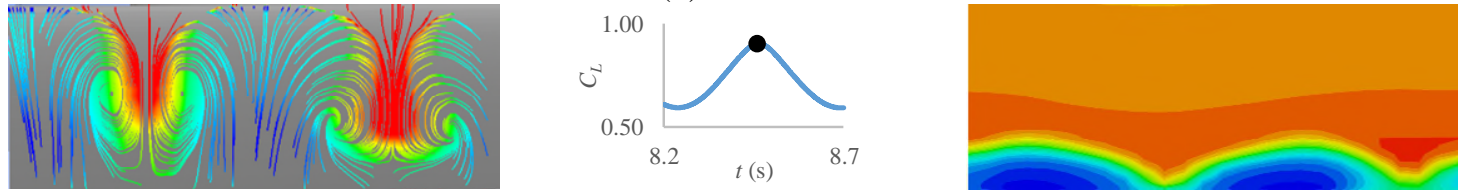

(c) $t=8.46 \mathrm{~s}$
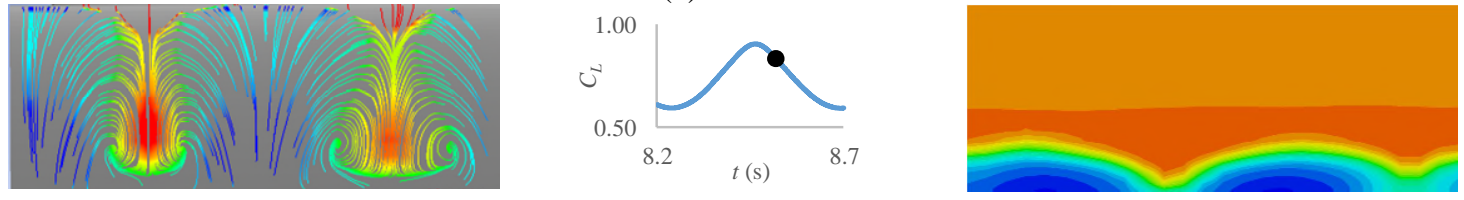

(d) $t=8.52 \mathrm{~s}$
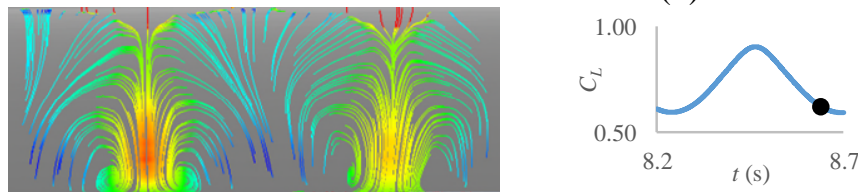

(e) $t=8.64 \mathrm{~s}$

Figure 10. Oscillation process of stall cells.

Left: skin-friction lines on the aerofoil upper surface.

Middle: lift coefficient.

Right: Stream-wise velocity field on Plane $2(\mathrm{x} / \mathrm{c}=0.5)$. $\mathrm{AoA}=18^{\circ}, \mathrm{AR}=2.5, \operatorname{Re}=1 \times 10^{6}, \Delta \mathrm{z}=0.1 \mathrm{c}($ Case 6$)$. 


\subsubsection{Effects of Aspect Ratio and Span-wise Resolution}

The results of Case 6-8 and 12-17 highlight the effects of aspect ratio and span-wise resolution on stall cell formation and oscillation. The average $C_{L}$ and standard deviation of $C_{L}$ oscillation for each case are shown in Table 3.

Table 3. Effects of AR and span-wise resolution. $R e=1 \times 10^{6}, \mathrm{AoA}=18^{\circ}$.

\begin{tabular}{cccccc}
\hline Case No. & AR & $\begin{array}{c}\text { Span-wise } \\
\text { Resolution }\end{array}$ & Average $\boldsymbol{C}_{\boldsymbol{L}}$ & $\begin{array}{c}\text { Standard } \\
\text { Deviation of } \boldsymbol{C}_{\boldsymbol{L}}\end{array}$ & $\begin{array}{c}\text { Number of } \\
\text { Stall Cells }\end{array}$ \\
\hline 6 & 2.5 & $0.1 \mathrm{c}$ & 0.742 & 0.0870 & 2 \\
7 (stage 1) & 2.5 & $0.05 \mathrm{c}$ & 0.697 & 0.0269 & 2 \\
7 (stage 2) & 2.5 & $0.05 \mathrm{c}$ & 0.679 & 0.0093 & 2 \\
8 & 2.5 & $0.025 \mathrm{c}$ & 0.649 & 0.0218 & $(2)$ \\
12 & 3.2 & $0.1 \mathrm{c}$ & 0.753 & 0.0795 & 2.5 \\
13 & 4 & $0.1 \mathrm{c}$ & 0.748 & 0.0773 & 3 \\
14 & 6.4 & $0.1 \mathrm{c}$ & 0.744 & 0.0514 & 4 \\
15 & 10 & $0.1 \mathrm{c}$ & 0.745 & 0.0411 & 7 \\
16 & 10 & $0.2 \mathrm{c}$ & 0.753 & 0 & 7 \\
17 & 10 & $0.05 \mathrm{c}$ & 0.690 & 0.0111 & 7 \\
\hline
\end{tabular}

The effect of AR on the average value of $C_{L}$ is very small. However, the standard deviation of $C_{L}$ decreases monotonically as $\mathrm{AR}$ increases, which suggests that more stable stall cells tend to form in a wider domain. The comparison between the $C_{L}$ oscillation of Case 6 and 15 (AR $=2.5$ and 10) has been presented earlier in Figure 8 as an example. The number of stall cells also increases approximately linearly with AR. This trend agrees with the experimental data of Winkelmann \& Barlow [4] and Yon et al. [3], although the exact number and the gradient do not match. The comparison is shown in Figure 11. It should be noted that the number of stall cells observed for AR = 10 in this study agrees with the earlier numerical study [6] and, as discussed in [6], this also agrees with the theoretical model prediction of Gross et al. [5], i.e. the stall cell size is proportional to the (negative) gradient of $C_{L}$ with respect to AoA.

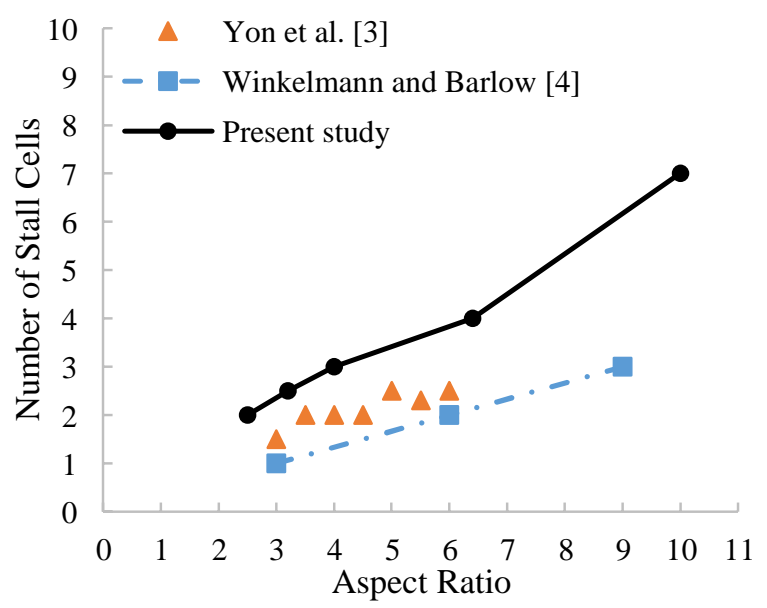

Figure 11. The relationship with aspect ratio and the number of stall cells.

The influence of the span-wise resolution can be illustrated with Case 6-8 (AR $=2.5)$, and Case 15-17 $(\mathrm{AR}=10)$. With $\Delta \mathrm{z}=0.2 \mathrm{c}$ (Case 16), the stall cells are found to be stationary and there 
is no fluctuation of the lift coefficient, presumably due to the insufficient resolution to capture the oscillation of stall cells. With $\Delta \mathrm{z}=0.05 \mathrm{c}$ (Case 7 and 17), stall cells are found to oscillate and again the standard deviation of $C_{L}$ decreases as AR increases, but the magnitude of the oscillation is less than the case with $\Delta \mathrm{z}=0.1 \mathrm{c}$ (Case 6 and 15). The value of the averaged $C_{L}$ is also slightly lower. The $C_{L}$ time history for Case 6-8 and 15-17 is shown in Figure 12. Interestingly, in Case 7, the oscillation of $C_{L}$ shows two different stages: the first stage is from around $4 \mathrm{~s}$ to around 12s (hereafter referred to as Case 7-1), where the $C_{L}$ oscillation is more irregular or chaotic. The second stage is from around $12 \mathrm{~s}$ to the end of the simulation (hereafter referred to as Case 7-2), where the $C_{L}$ follows an almost perfectly periodic oscillation and the stall cells are almost steady and fluctuating only slightly. The difference between Case $8(\Delta \mathrm{z}=$ $0.025 \mathrm{c})$ and Case $7(\Delta z=0.05 \mathrm{c})$ is not as significant as between Case 7 and Case $6(\Delta \mathrm{z}=0.1 \mathrm{c})$, even though the average $C_{L}$ value is still lower for Case 8 . The reason for the smaller oscillations for $\Delta \mathrm{z}=0.05 \mathrm{c}$ and $0.025 \mathrm{c}$ is not very clear at this stage, although a possible explanation is that the finer span-wise resolution allows the growth of shorter-wavelength instabilities, reducing the growth of the (otherwise dominant) long-wavelength oscillations.

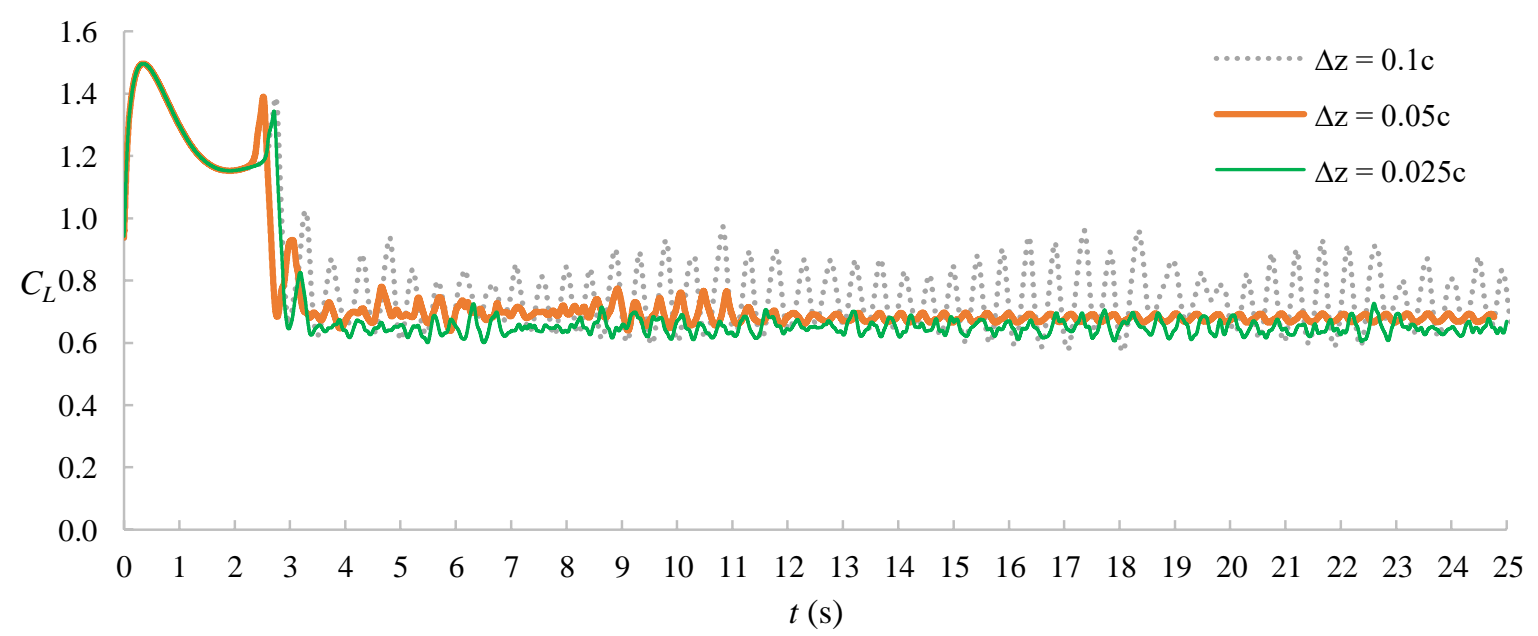

(a) $C_{L}$ time history. $R e=1 \times 10^{6}, \mathrm{AR}=2.5, \mathrm{AoA}=18^{\circ}, \Delta \mathrm{z}=0.025 \mathrm{c}, 0.05 \mathrm{c}$ and $0.1 \mathrm{c}$.

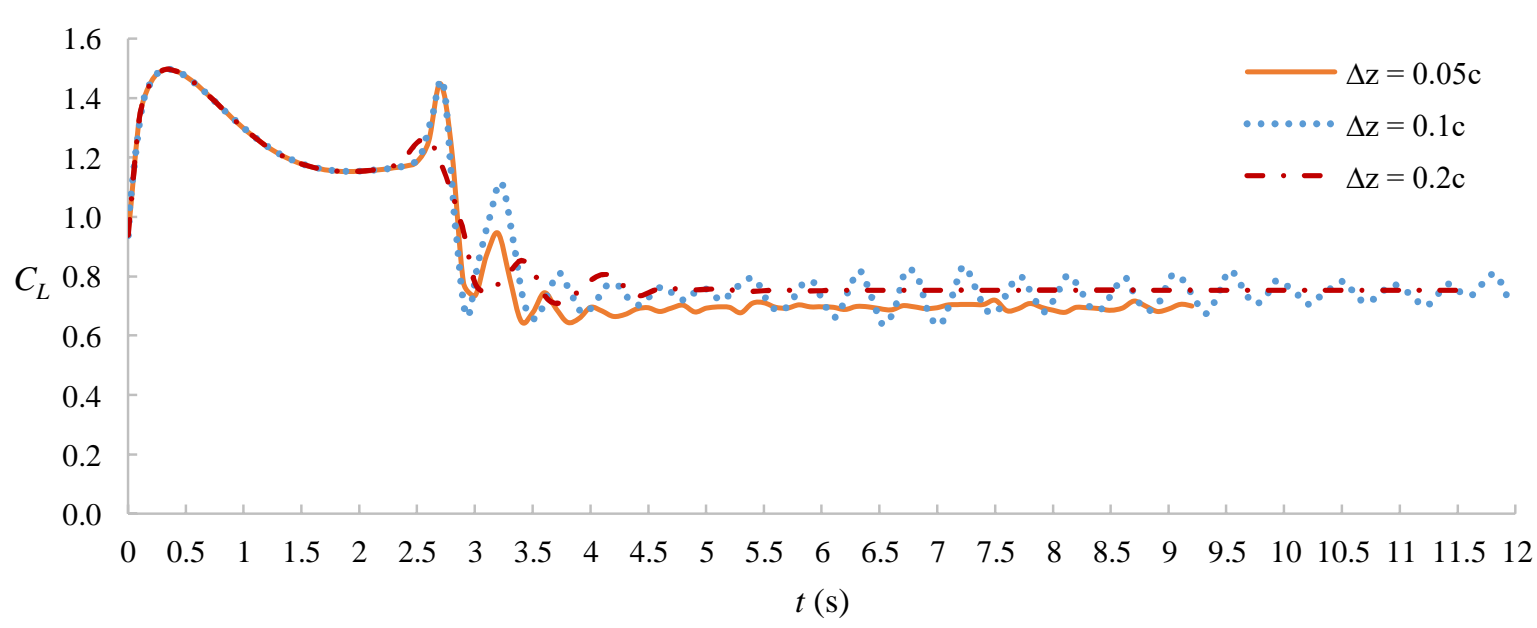

(b) $C_{L}$ time history. $R e=1 \times 10^{6}, \mathrm{AR}=10, \mathrm{AoA}=18^{\circ}, \Delta \mathrm{z}=0.05 \mathrm{c}, 0.1 \mathrm{c}$ and $0.2 \mathrm{c}$.

Figure 12. Effects of span-wise resolution on $C_{L}$ oscillation. (a) Case 4-6, (b) Case 15-17. 

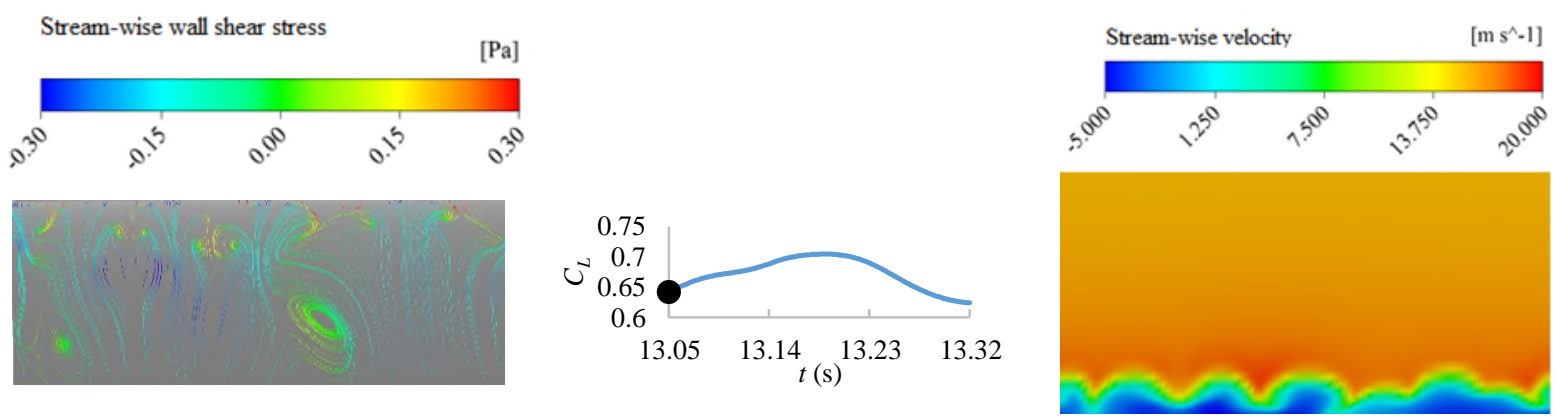

(a) $13.05 \mathrm{~s}$
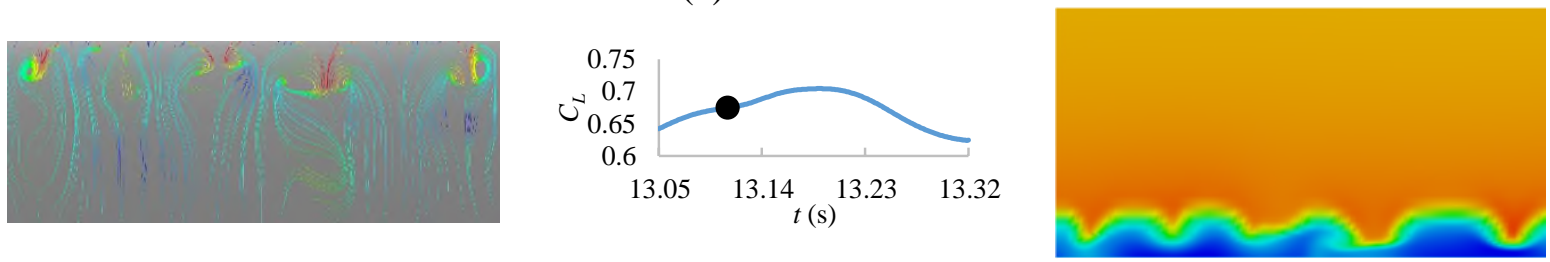

(b) $13.11 \mathrm{~s}$
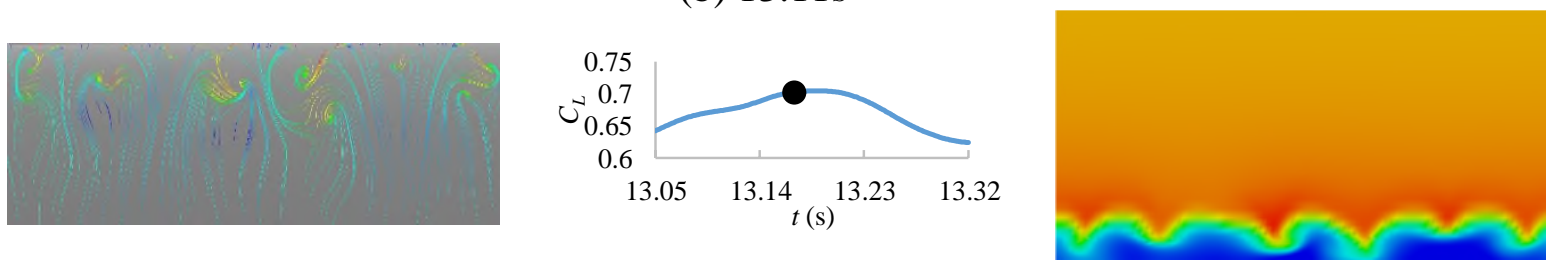

(c) $13.17 \mathrm{~s}$
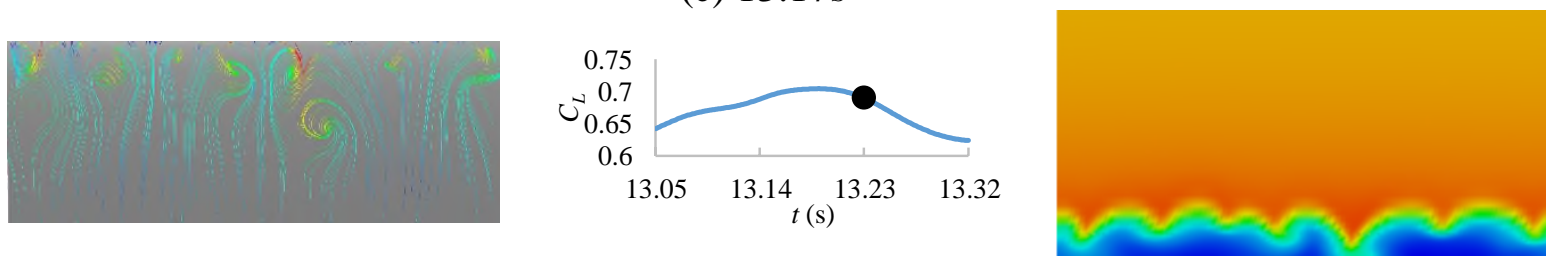

(d) $13.23 \mathrm{~s}$
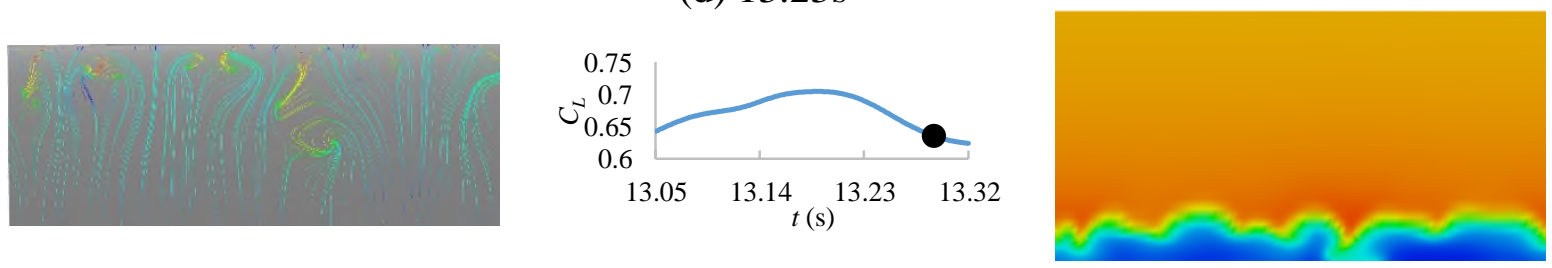

(e) $13.29 \mathrm{~s}$

Figure 13. Oscillation process of stall cells.

Left: skin-friction lines on the aerofoil upper surface.

Middle: lift coefficient.

Right: Stream-wise velocity field on Plane $2(\mathrm{x} / \mathrm{c}=0.5)$.

$\mathrm{AoA}=18^{\circ}, \mathrm{AR}=2.5, \operatorname{Re}=1 \times 10^{6}, \Delta \mathrm{z}=0.025 \mathrm{c}($ Case 8$)$.

Figure 13 shows the oscillation process of stall cells for Case $8(\Delta z=0.025 c ; 13.02 s-13.32 s)$. The expansion and shrinkage of the separated/attached area observed earlier for Case 6 (Figure 10) are still observed in this case. However, the flow structures observed in this case on and above the aerofoil upper surface appear to be much smaller compared to Case 6. Nevertheless, it is still possible to recognise two large stall-cell-like structures, especially from the streamwise velocity contours showing two distinct regions of negative stream-wise velocity values. This can also be confirmed from the fast Fourier transform (FFT) analysis of the span-wise variation of time-averaged stream-wise velocity at Plane 2 as shown in Figure 14. The velocity data were sampled across the entire span of the computational domain at an arbitrary vertical 
position ( $y=0.14 \mathrm{c}$, which is approximately in the middle of the separated flow regions) but the results are not sensitive to this sampling position. It can be seen that the dominant spatial frequency is the same for all cases including Case 8, indicating the existence of two large structures, even though a clear secondary peak (corresponding to smaller-scale sub-structures) is also observed for Case 8.

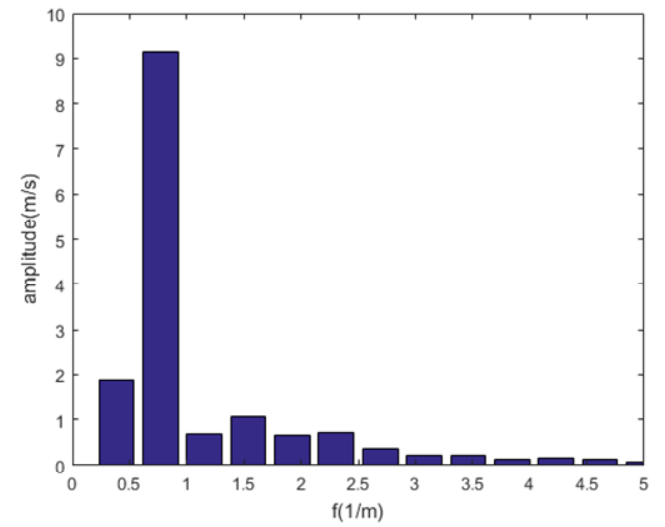

(a) Case 6

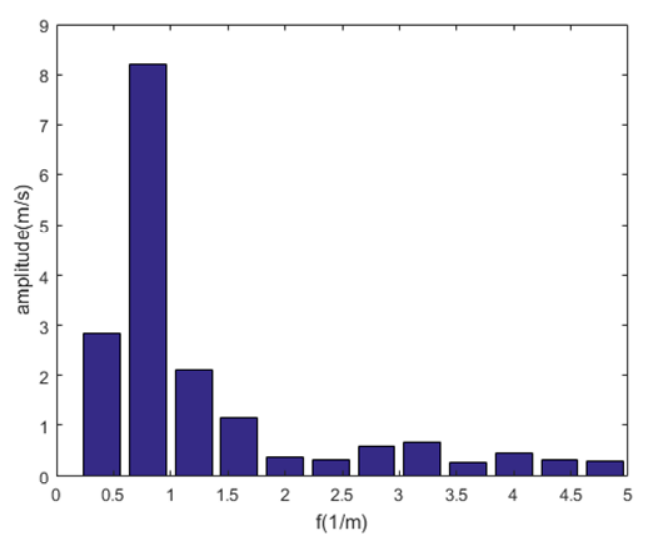

(c) Case 7-2

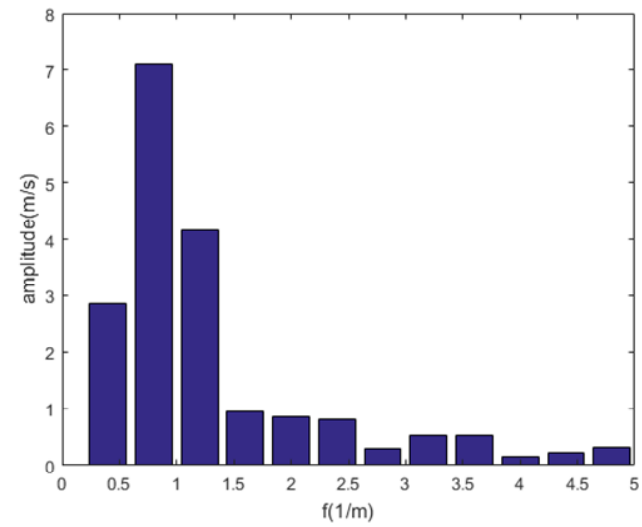

(b) Case 7-1

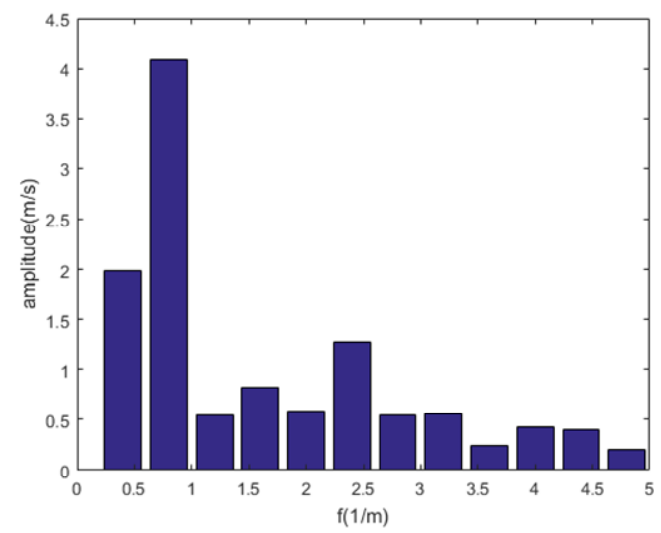

(d) Case 8

Figure 14. FFT analysis of the span-wise variation of the time-averaged stream-wise velocity. Case 6, 7-1, 7-2 and 8.

The above results show clearly that the flow structures captured in these 3D unsteady RANS simulations are dependent on the span-wise resolution. However, it should be noted that the smaller-scale flow structures observed in Case 8 are still loosely organised and are therefore different from fully turbulent eddies commonly captured in large-eddy simulations (LES) and hybrid RANS-LES methods, such as those observed in the delayed detached-eddy simulations (DDES) reported in [6] for the same flow configuration. This seems understandable since unsteady RANS simulations are able to capture only certain types of unsteady flow structures (due to certain types of flow instabilities that are strong enough for disturbances to grow even in the 'Reynolds-averaged' flow with modelled Reynolds stresses or eddy viscosity, such as the von-Karman type vortices behind a bluff body). From the current limited set of results, it is impossible to know the minimum size of flow structures that could be captured by further increasing the span-wise resolution of these RANS simulations. It should also be noted that the numerical solver used in this study does not employ high-order schemes and therefore, these results may be affected by discretisation errors to some extent. Nevertheless, it is worth noting that a recent study by Kamenetskiy et al. [30] has shown that, for a similar type of separated flow over an aerofoil at stall, 3D RANS simulations could yield multiple (bifurcated) solutions even with machine-zero residuals obtained using high-order schemes. This suggests that it may 
not be possible to obtain a 'grid-converged' solution from 3D RANS simulations of this type of flow over an aerofoil at stall.

\subsection{POD Analysis}

Snapshot POD analysis of the flow over the aerofoil is presented to further investigate the oscillatory characteristics of stall cells. The analysis is performed with four different data sets: Case $6(\Delta \mathrm{z}=0.1 \mathrm{c})$ with a sampling interval of $0.05 \mathrm{~s}$, Case $7-1$ and $7-2(\Delta \mathrm{z}=0.05 \mathrm{c})$ with a sampling interval of $0.04 \mathrm{~s}$, respectively, and Case $8(\Delta \mathrm{z}=0.025 \mathrm{c})$ with a sampling interval of $0.03 \mathrm{~s}$. For each data set, 100 snapshots are taken and the POD modes are calculated following the procedures shown in Section 2.4. Each mode contains a certain percentage of the total kinetic energy of the flow field. The cumulative kinetic energy of mode 1 to 14 is shown in Figure 15 for the four different data sets on Plane $2(x / c=0.5)$. In the actual computation process, the first mode obtained corresponds to the time-averaged velocity field and it occupies most of the kinetic energy. In this study, this mode is denoted as 'Mode 0' and excluded from the consideration of the cumulative kinetic energy. The similarity between 'Mode 0' and the mean velocity field is shown in Figure 16.

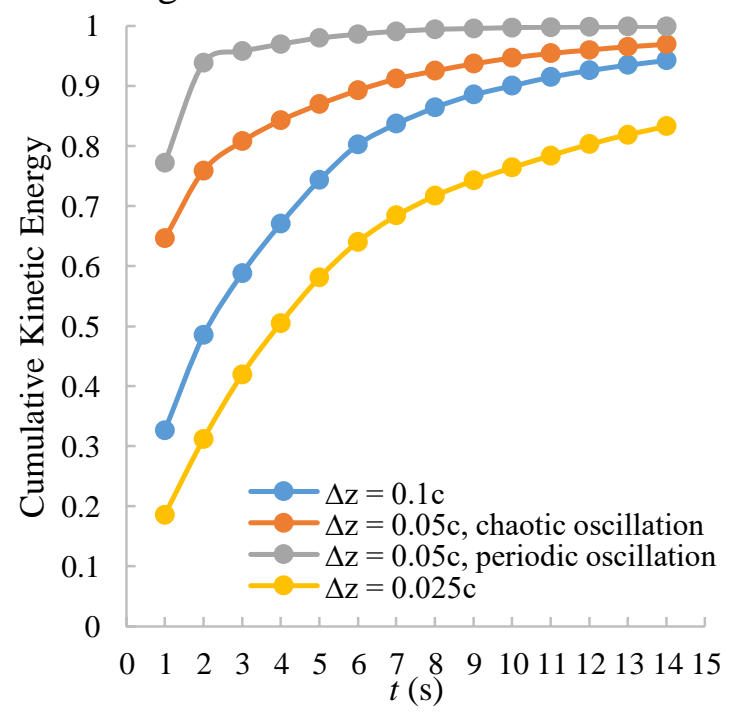

Figure 15. Cumulative kinetic energy for the first 14 POD modes.

$R e=1 \times 10^{6}, \mathrm{AR}=2.5, \mathrm{AoA}=18$. Plane $2: \mathrm{x}=0.5 \mathrm{c}$. Case 6, 7-1, 7-2 and 8.

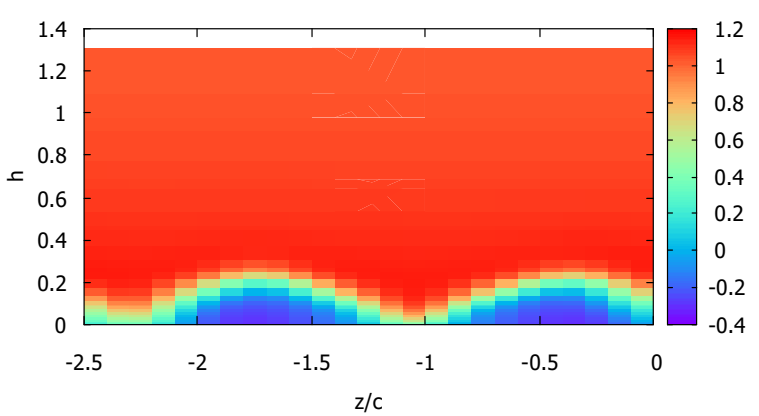

(a) Mode 0

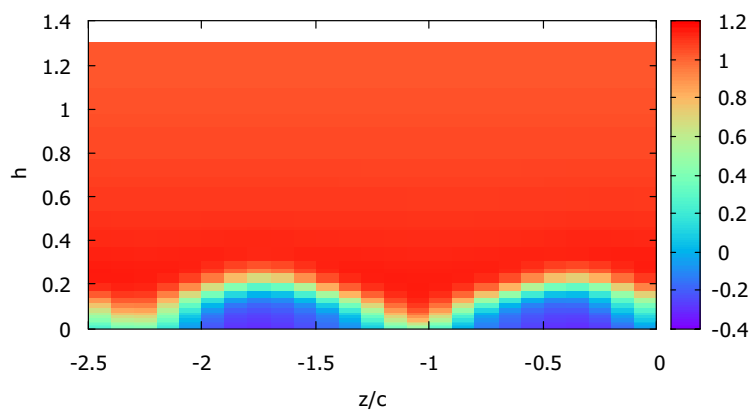

(b) Time-averaged velocity field.

Figure 16 . Mode 0 and the time-averaged velocity field at $x / c=0.5$ (Case 6).

As Figure 15 shows, the cumulative kinetic energy for each mode differs significantly from case to case. For Case 7-2, for example, the first two modes take 93.8\% of the total energy, 
which suggests that these two modes are mostly responsible for the dominant dynamics of the flow (i.e. oscillation of stall cells). However, for Case 8, the first 14 modes take only $83.2 \%$ of the total energy. Figure 17 shows a comparison of the FFT analysis of the time variation of $C_{L}$ for the four cases. Two very clear peaks are observed for Case 7-2, whereas Case 8 shows a rather noisy spectrum. This is consistent with the fact that a large number of POD modes are required to represent the unsteady flow field for Case 8, whereas only the first few modes are required for Case 7-2.

Figure 18 shows the visualisation of the first three POD modes for Case 6 at three different chord-wise positions (Plane 1, 2 and 3, corresponding to $x / c=0.2,0.5$ and 0.8 ). It is worth noting that these energetically dominant modes show clear patterns over the side edges of the separated flow regions. It can also be observed that the size of these flow structures grow in the vertical direction as the flow travels along the chord-wise direction (from $x / c=0.2$ to 0.5 and 0.8). Figure 19 shows the first three POD modes for Case 7-1 (chaotic $C_{L}$ oscillation period) and Case 7-2 (periodic $C_{L}$ oscillation period). The patterns observed in these POD modes are similar to those observed for Case 6 in Figure 18. However, these structures are smaller and more limited to the side edges of the separated flow regions compared to Case 6 .

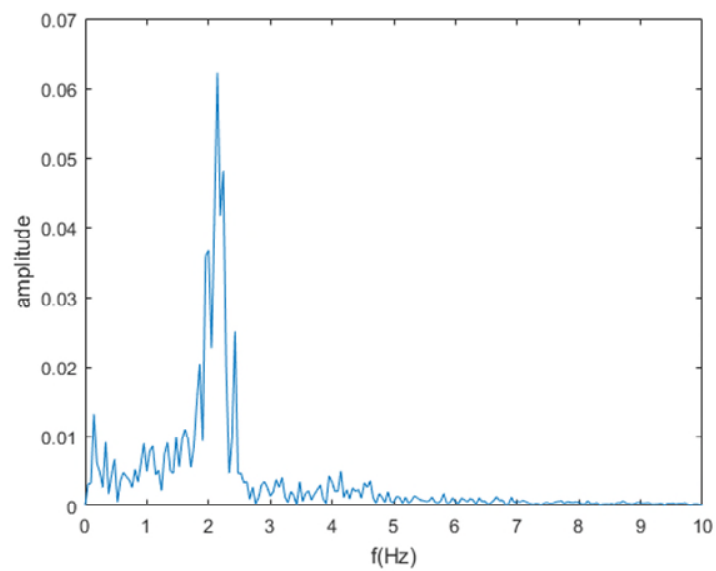

(a) Case 6

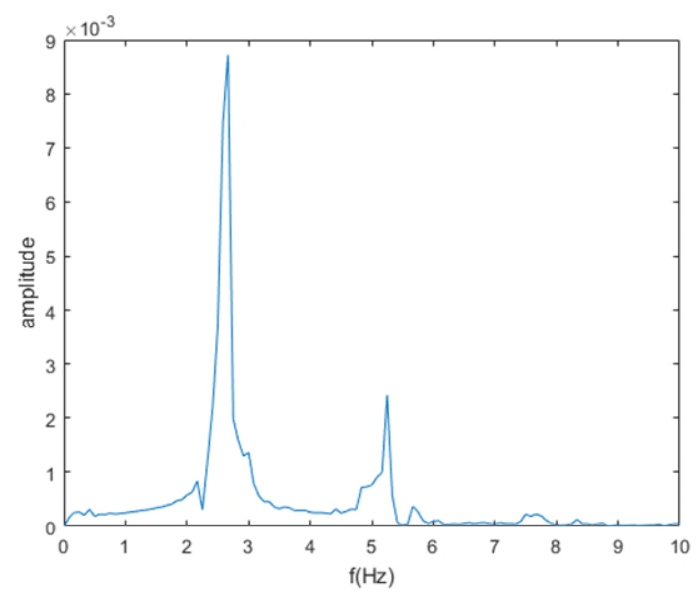

(c) Case 7-2

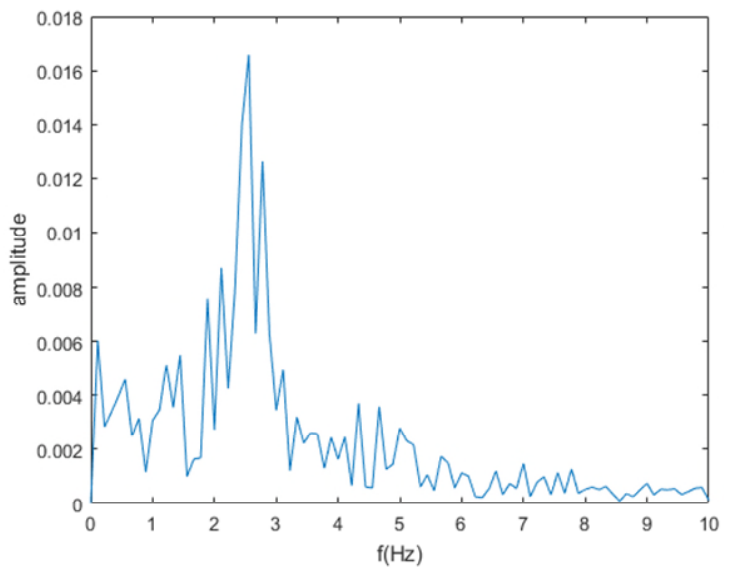

(b) Case 7-1

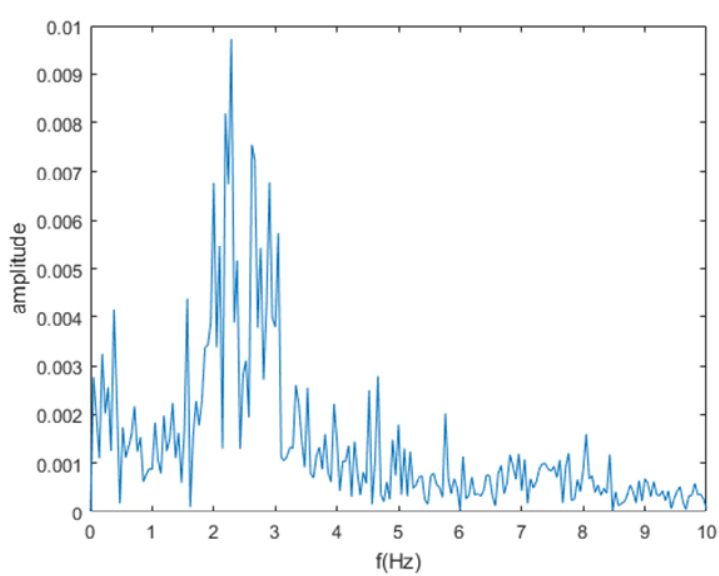

(d) Case 8

Figure 17. FFT analysis of the time variation of $C_{L}$ for Case $6,7-1,7-2$ and 8. 


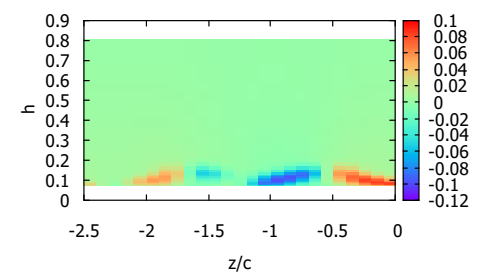

(a) Plane 1, Mode 1

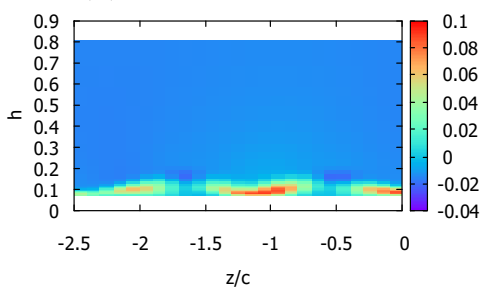

(b) Plane 1, Mode 2

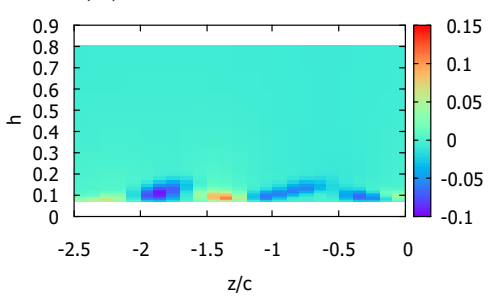

(c) Plane 1, Mode 3

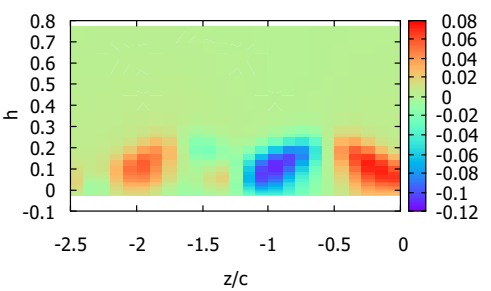

(d) Plane 2, Mode 1

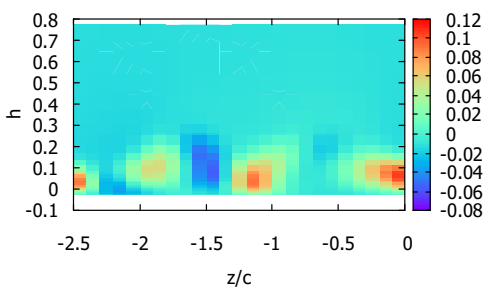

(e) Plane 2, Mode 2

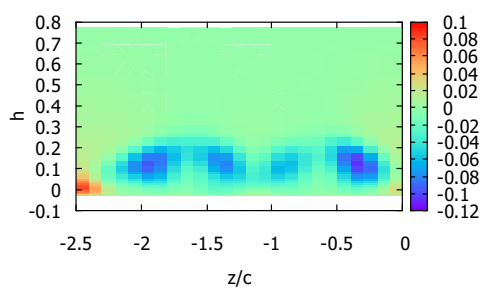

(f) Plane 2, Mode 3

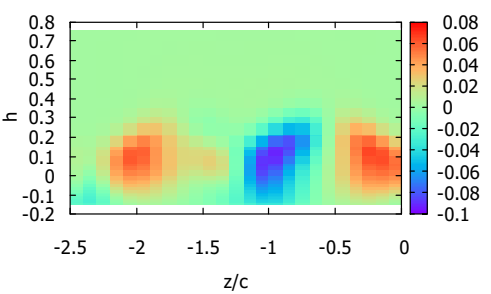

(g) Plane 3, Mode 1

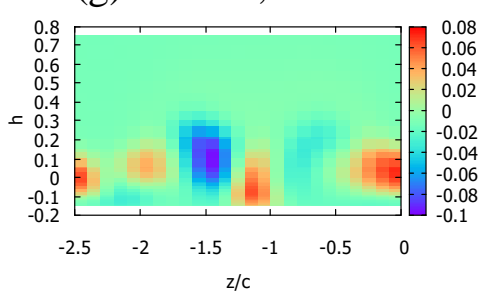

(h) Plane 3, Mode 2

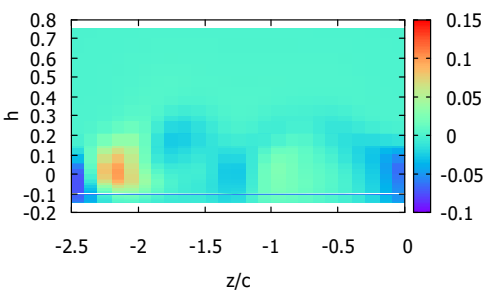

(i) Plane 3, Mode 3

Figure 18. First three POD modes for Case 6.

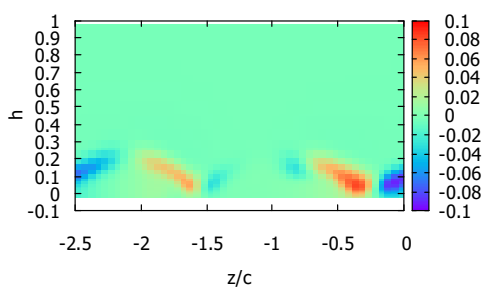

(a) Chaotic $C_{L}$ oscillation, Mode 1

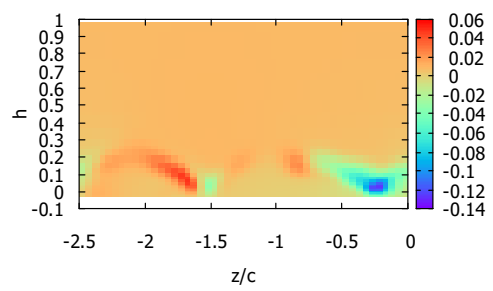

(b) Chaotic $C_{L}$ oscillation, Mode 2

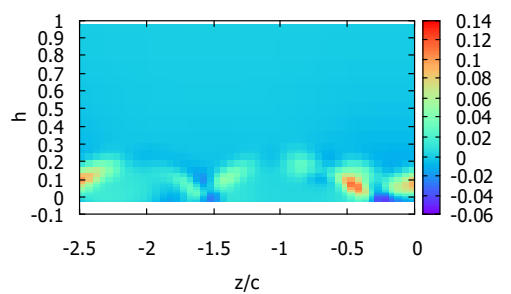

(c) Chaotic $C_{L}$ oscillation, Mode 3

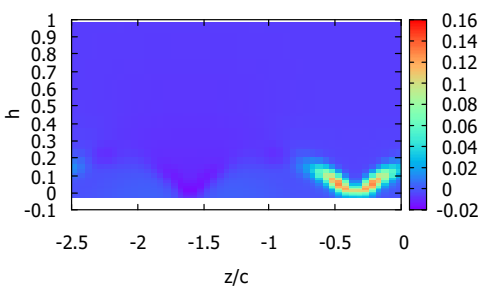

(d) Periodic $C_{L}$ oscillation, Mode 1

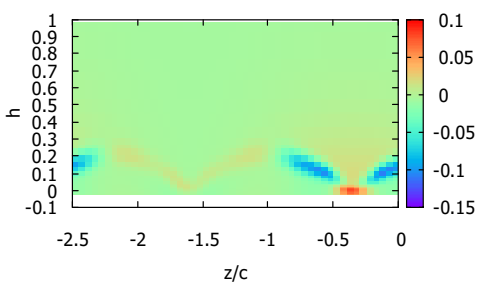

(e) Periodic $C_{L}$ oscillation, Mode 2

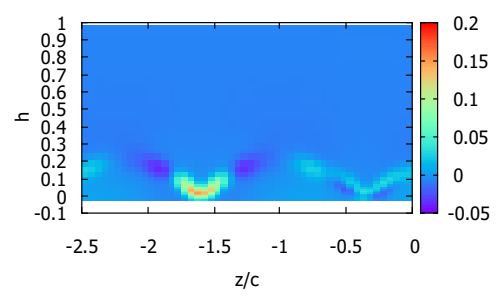

(f) Periodic $C_{L}$ oscillation, Mode 3

Figure 19. First three POD modes for Case 7 at Plane 2. 
Figure 20 shows a comparison between the fluctuation of $C_{L}$ and the fluctuations of the time coefficients of Mode $1\left(a_{1}\right)$, Mode $2\left(a_{2}\right)$ and Mode $3\left(a_{3}\right)$ at Plane $2(x / c=0.5)$ for Case 7-2 during the same period of time. Although the exact patterns of the oscillations do not match, the frequency of the oscillation of Mode 1 and 2 agree with that of the lift coefficient, whereas Mode 3 has a higher frequency. The same behaviour can also be observed at the other two planes $(x / c=0.2$ and 0.8$)$. This means that Mode 1 and 2 correspond to the oscillation of stall cells as well as the lift oscillation. This correlation can be observed for Case 6 and Case 7-1 as well. However, it is difficult to detect this correlation for Case 8 since the frequency spectrum is rather noisy (as shown earlier in Figure 17).

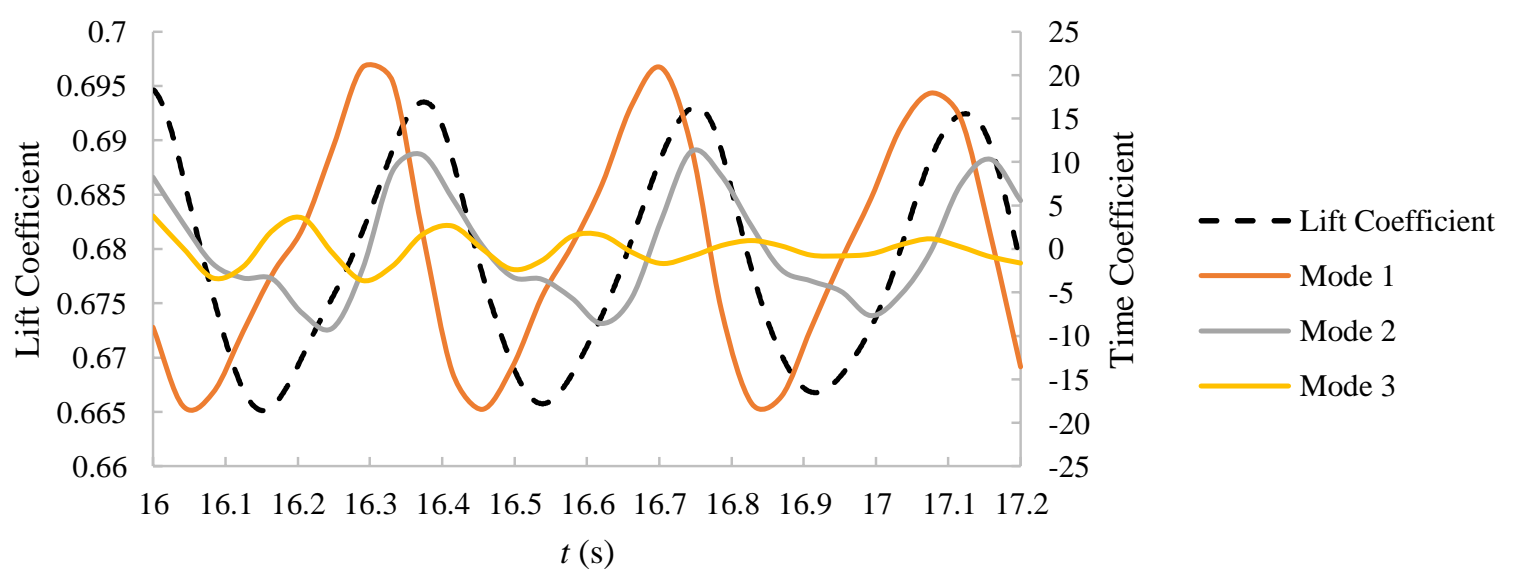

Figure 20. Fluctuations of the lift coefficient and Mode 1-3 time coefficients at Plane 2. Case 7-2.

\section{Conclusions}

A series of 3D unsteady RANS simulations have been conducted using (fully turbulent) $k-\omega$ SST model to investigate the influence of several parameters on the formation and oscillation of stall cells over a NACA 0012 aerofoil, with periodic boundary conditions applied to the span-wise ends of the computational domain. The parameters investigated are: two different Reynolds numbers $\left(1.35 \times 10^{5}\right.$ and $\left.1 \times 10^{6}\right)$, five different aspect ratios $(2.5,3.2,4,6.4$ and 10), four different span-wise mesh resolutions $(2.5 \%, 5 \%, 10 \%$ and $20 \%$ chord) and a range of angles of attack (AoA). The results show that the higher Reynolds number gives a larger range of AoA that allows the formation of stall cells. Within this AoA range, the mean lift coefficient decreases as AoA increases, which is consistent with the outcome of the earlier computational study of Manni et al. [6] as well as the theoretical study of Gross et al.[5].

In the majority of simulations performed with a medium level of span-wise mesh resolution (10\% chord), stall cells exhibit strong unsteady behaviour, travelling repeatedly from the leading edge to the trailing edge. Although this unsteady motion appears to be similar to the 'jostling' motion reported earlier in [3], the current computational results show for the first time (to the authors' knowledge) a clear correlation between the fluctuation of lift coefficient and the oscillation of stall cells.

With regard to the influence of the aspect ratio, the stall cell oscillations and the resultant lift fluctuations become less significant as the aspect ratio increases, although the timeaveraged lift coefficient does not change substantially with it. The number of the stall cells 
observed has an approximately linear relationship with the aspect ratio, which agrees with previous experimental results [3] [4].

As for the influence of four different span-wise mesh resolutions, stall cells are found to be stationary (and so is the lift) for the case with the coarsest resolution (20\% chord). This is in contrast to the strong unsteadiness observed with the medium resolution (10\% chord), suggesting that the coarsest resolution tested in this study is insufficient to capture the instability of stall cells. With the finer (5\% chord) and finest $(2.5 \%$ chord) span-wise resolutions, however, this unsteadiness is found to be less significant than the case with the medium resolution. For the finest span-wise resolution case, small-scale flow structures (substructures) are observed on top of large stall-cell-like structures. These sub-structures are loosely organised and are therefore different from fully turbulent eddies commonly captured in large-eddy simulations (LES) and hybrid RANS-LES methods. Further investigations are required in the future, ideally with higher-order numerical schemes, to confirm the minimum size of flow structures that could be captured by further increasing the span-wise resolution and whether or not a 'grid-converged' solution could be obtained from 3D RANS simulations of this type of flow over an aerofoil at stall.

Finally, the POD analysis has been conducted to further investigate the characteristics of stall cell oscillations and lift fluctuation. In particular, the first few POD modes are found to have clear spatial patterns corresponding to the profile of stall cells, and the fluctuations of their temporal coefficients are found to be correlated with the lift fluctuation, which further confirms the correlation between the stall cell oscillations and the lift fluctuation.

\section{ACKNOWLEDGEMENT}

The authors would like to thank Dr Pierre-Luc Delafin for his technical assistance during the initial stage of this study. 


\section{REFERENCES}

[1] Moss, G. F., \& Murdin, P. M. Two Dimensional Low-speed Tunnel Tests on the NACA 0012 Section Including Measurements Made During Pitching Oscillations at the Stall. Royal Aircraft Establishment (Great Britain), 1968

[2] Broeren, A. P., \& Bragg, M. B. Spanwise variation in the unsteady stalling flowfields of two-dimensional airfoil models. AIAA journal, 39(9), 1641-1651, 2001.

[3] Yon, S. A., \& Katz, J. Study of the unsteady flow features on a stalled wing. AIAA journal, 36(3), 305-312, 1998.

[4] Winkelman, A. E., \& Barlow, J. B. Flowfield model for a rectangular planform wing beyond stall. AIAA Journal, 18(8), 1006-1008, 1980.

[5] Gross, A., Fasel, H. F., \& Gaster, M. Criterion for spanwise spacing of stall cells. AIAA Journal, 53(1), 272-274, 2014.

[6] Manni, L., Nishino, T., \& Delafin, P. L. Numerical study of airfoil stall cells using a very wide computational domain. Computers \& Fluids, 140, 260-269, 2016.

[7] Zarutskaya, T., \& Arieli, R. On vortical flow structures at wing stall and beyond. In 35th AIAA Fluid Dynamics Conference and Exhibit (p. 4913), 2005.

[8] Rodriguez, D., \& Theofilis, V. Structural changes of laminar separation bubbles induced by global linear instability. Journal of Fluid Mechanics, 655, 280-305, 2010.

[9] Rodríguez, D., \& Theofilis, V. On the birth of stall cells on airfoils. Theoretical and Computational Fluid Dynamics, 25(1), 105-117, 2011.

[10] Disotell, K. J., Nikoueeyan, P., Naughton, J. W., \& Gregory, J. W. Global surface pressure measurements of static and dynamic stall on a wind turbine airfoil at low Reynolds number. Experiments in Fluids, 57(5), 1-15, 2016.

[11] Manolesos, M., Papadakis, G., \& Voutsinas, S. G. Experimental and computational analysis of stall cells on rectangular wings. Wind Energy, 17(6), 939-955, 2014.

[12] Elimelech, Y., Arieli, R., \& Iosilevskii, G. The three-dimensional transition stages over the NACA-0009 airfoil at Reynolds numbers of several ten thousand. Physics of Fluids, 24(2), 024104, 2012.

[13] Dell'Orso, H., Chan, W., \& Amitay, M. Induced Stall Cells on a NACA0015 Airfoil using Passive and Active Trips. In 8th AIAA Flow Control Conference (p. 3621), 2016.

[14] Ragni, D., \& Ferreira, C. Effect of 3D stall-cells on the pressure distribution of a laminar NACA64-418 wing. Experiments in Fluids, 57(8), 127, 2016.

[15] Pearson, K. (1901). LIII. On lines and planes of closest fit to systems of points in space. The London, Edinburgh, and Dublin Philosophical Magazine and Journal of Science, 2(11), 559-572.

[16] Lumley, J. L. (1967). The structure of inhomogeneous turbulent flows. Atmospheric turbulence and radio wave propagation.

[17] Rempfer, D., \& Fasel, H. F. (1994). Evolution of three-dimensional coherent structures in a flat-plate boundary layer. Journal of Fluid Mechanics, 260, 351-375.

[18] Meyer, K. E., Pedersen, J. M., \& Özcan, O. (2007). A turbulent jet in crossflow analysed with proper orthogonal decomposition. Journal of Fluid Mechanics, 583, 199-227.

[19] Kostas, J., Soria, J., \& Chong, M. S. (2005). A comparison between snapshot POD analysis of PIV velocity and vorticity data. Experiments in Fluids, 38(2), 146-160.

[20] Van Oudheusden, B. W., Scarano, F., Van Hinsberg, N. P., \& Watt, D. W. (2005). Phase-resolved characterization of vortex shedding in the near wake of a square-section cylinder at incidence. Experiments in Fluids, 39(1), 86-98.

[21] Galletti, B., Bruneau, C. H., Zannetti, L., \& Iollo, A. (2004). Low-order modelling of laminar flow regimes past a confined square cylinder. Journal of Fluid Mechanics, 503, 161170 . 
[22] Bui-Thanh, T., Damodaran, M., \& Willcox, K. (2004). Aerodynamic data reconstruction and inverse design using proper orthogonal decomposition. AIAA journal, 42(8), 1505-1516.

[23] Druault, P., Lardeau, S., Bonnet, J. P., Coiffet, F., Delville, J., Lamballais, E., ... \& Perret, L. (2004). Generation of three-dimensional turbulent inlet conditions for large-eddy simulation. AIAA journal, 42(3), 447-456.

[24] Barbagallo, A., Sipp, D., \& Schmid, P. J. (2009). Closed-loop control of an open cavity flow using reduced-order models. Journal of Fluid Mechanics, 641, 1-50.

[25] Lee, T., \& Gerontakos, P. Investigation of flow over an oscillating airfoil. Journal of Fluid Mechanics, 512, 313, 2004.

[26] Shen, X., Avital, E., Rezaienia, M. A., Paul, G., \& Korakianitis, T. (2017). Computational methods for investigation of surface curvature effects on airfoil boundary layer behavior. Journal of Algorithms \& Computational Technology, 11(1), 68-82.

[27] Menter, F. R. (1994). Two-equation eddy-viscosity turbulence models for engineering applications. AIAA journal, 32(8), 1598-1605.

[28] Sirovich, L. (1987). Turbulence and the dynamics of coherent structures. I. Coherent structures. Quarterly of applied mathematics, 45(3), 561-571.

[29] Chen, H., Reuss, D. L., Hung, D. L., \& Sick, V. (2013). A practical guide for using proper orthogonal decomposition in engine research. International Journal of Engine Research, 14(4), 307-319.

[30] Kamenetskiy, D. S., Bussoletti, J. E., Hilmes, C. L., Venkatakrishnan, V., Wigton, L. B., \& Johnson, F. T. (2014). Numerical evidence of multiple solutions for the Reynoldsaveraged Navier-Stokes equations. AIAA journal, 52(8), 1686-1698. 